\title{
Delivery strategies to enhance oral vaccination against enteric infections ${ }^{\text {咨 }}$
}

\author{
Christopher J.H. Davitt ${ }^{\mathrm{a}}$, Ed C. Lavelle ${ }^{\mathrm{a}, \mathrm{b}, *}$ \\ a Adjuvant Research Group, School of Biochemistry and Immunology, Trinity Biomedical Sciences Institute, Trinity College Dublin, Dublin 2, Ireland \\ ${ }^{\mathrm{b}}$ Centre for Research on Adaptive Nanostructures and Nanodevices (CRANN) E Advanced Materials Bio-Engineering Research Centre (AMBER), Trinity College Dublin, Dublin 2, Ireland
}

\section{A R T I C L E I N F O}

Available online $\mathrm{xxxx}$

\section{Keywords:}

Delivery system

Adjuvant

Nanoparticle

Mucosal

Gastrointestinal

Oral

Vaccine

\begin{abstract}
A B S T R A C T
While the majority of human pathogens infect the body through mucosal sites, most licensed vaccines are injectable. In fact the only mucosal vaccine that has been widely used globally for infant and childhood vaccination programs is the oral polio vaccine (OPV) developed by Albert Sabin in the 1950s. While oral vaccines against Cholera, rotavirus and Salmonella typhi have also been licensed, the development of additional non-living oral vaccines against these and other enteric pathogens has been slow and challenging. Mucosal vaccines can elicit protective immunity at the gut mucosa, in part via antigen-specific secretory immunoglobulin A (SIgA). However, despite their advantages over the injectable route, oral vaccines face many hurdles. A key challenge lies in design of delivery strategies that can protect antigens from degradation in the stomach and intestine, incorporate appropriate immune-stimulatory adjuvants and control release at the appropriate gastrointestinal site. A number of systems including micro and nanoparticles, lipid-based strategies and enteric capsules have significant potential either alone or in advanced combined formulations to enhance intestinal immune responses. In this review we will outline the opportunities, challenges and potential delivery solutions to facilitate the development of improved oral vaccines for infectious enteric diseases.
\end{abstract}

C 2015 Elsevier B.V. All rights reserved.

\section{Contents}

1. Introduction ........... 0

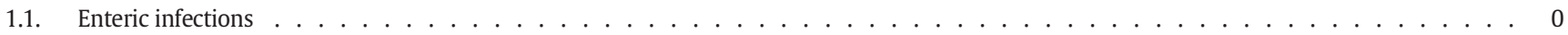

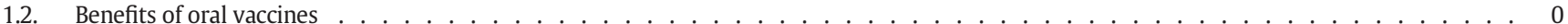

1.3. Challenges of developing new oral vaccines . . . . . . . . . . . . . . . . . . . . . . . . . 0

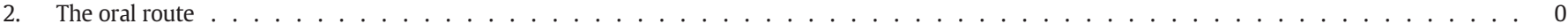

2.1. Physical and chemical barriers . . . . . . . . . . . . . . . . . . . . . . . . . . . . . . . . 0

2.2. Poor mucosal immunogenicity (hypo-responsiveness and tolerance) . . . . . . . . . . . . . . . . . . . . . . 0

3. Immune Responses to enteric infections . . . . . . . . . . . . . . . . . . . . . . . . . . . . . . . . . . 0

3.1. Antigen uptake in the gut $\ldots \ldots \ldots \ldots$

Abbreviations: APC, antigen presenting cell; BCG, Bacillus Calmette-Guérin; cAMP, cyclic adenosine monophosphate; CDCA, chenodeoxycholic acid; CFA, colonisation factor antigen;

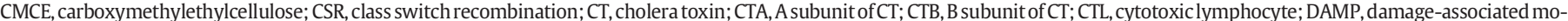

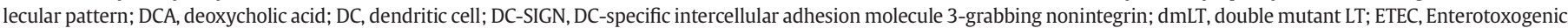

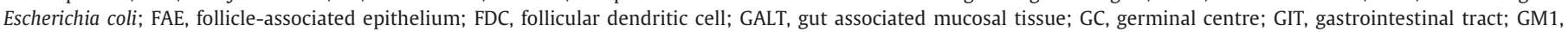

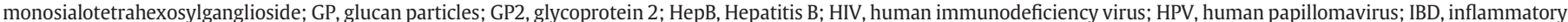

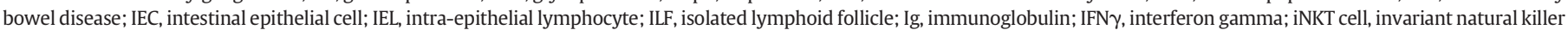

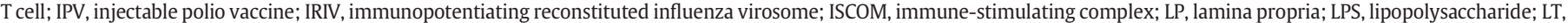

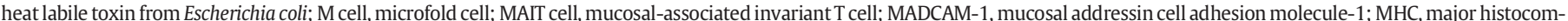

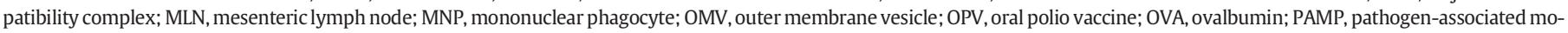

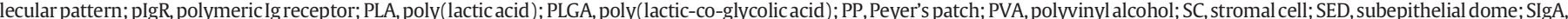

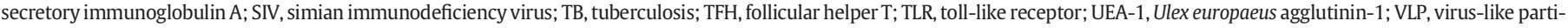
cles; WCK, whole cell killed; UN, United Nations

is This review is part of the Advanced Drug Delivery Reviews theme issue on "Editor's Choice 2015".

* Corresponding author at: Adjuvant Research Group, School of Biochemistry and Immunology, Trinity Biomedical Sciences Institute, Trinity College Dublin, Dublin 2, Ireland. Tel.: + 353 1 8962488; fax: + 35316772400 .

E-mail address: lavellee@tcd.ie (E.C. Lavelle). 


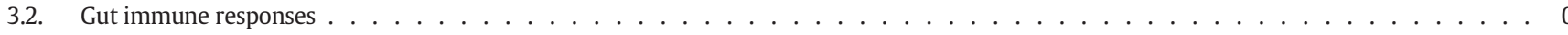

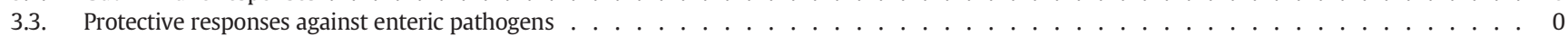

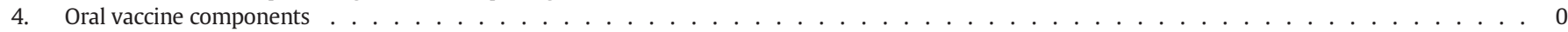

4.1. Classes of mucosal antigen . . . . . . . . . . . . . . . . . . . . . . . . . . . . . . . 0

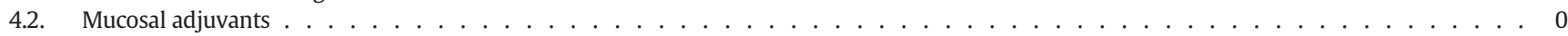

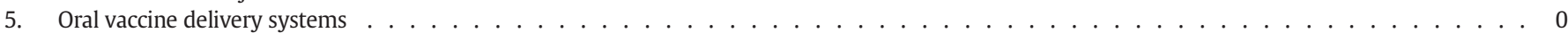

5.1. Lipid based delivery systems: emulsions, liposomes and ISCOMs ． . . . . . . . . . . . . . . . . . . . . . . . . . . . . . 0

5.1.1. Liposomes . . . . . . . . . . . . . . . . . . . . . . . . . . . . . . . . 0

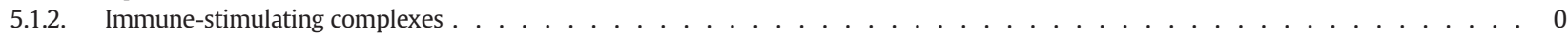

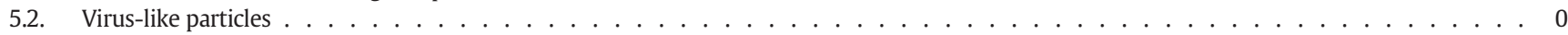

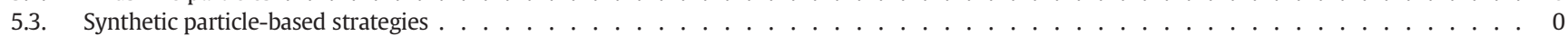

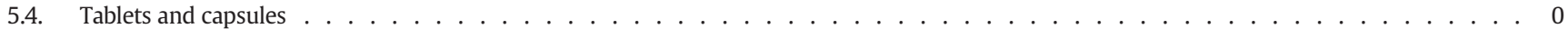

6. Technical adaptations to oral delivery vehicles . . . . . . . . . . . . . . . . . . . . . . . . . . . . . . . . . . . 0

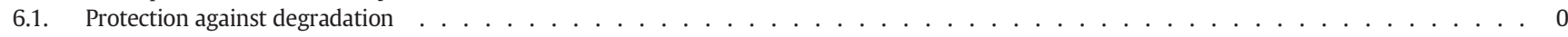

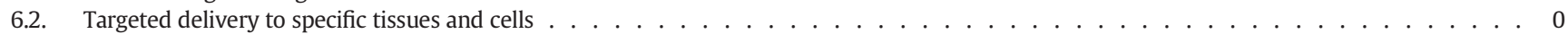

6.3. Muco-adhesion and delivery $\ldots \ldots \ldots \ldots \ldots \ldots$

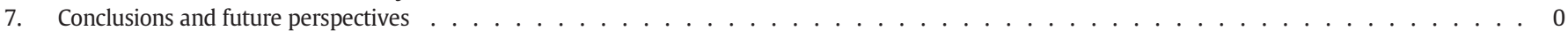

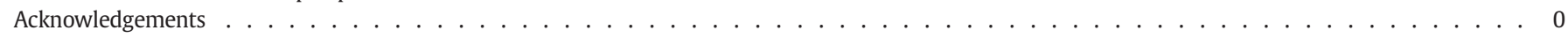

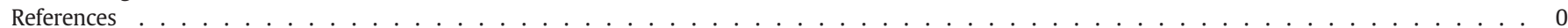

\section{Introduction}

\subsection{Enteric infections}

Infectious diarrhoea is a significant global health challenge. Most diarrhoeal diseases are spread via the faecal oral route, primarily through contaminated water and food, resulting from poor sanitation. In the developed world, diarrhoeal diseases account for significant morbidity whereas in the developing world, where sanitation systems are often sub-optimal, it is associated with high levels of mortality [1], especially in children under 5 years of age who are most at risk at contracting and succumbing to such diseases [2]. Although oral rehydration therapy has reduced the overall number of fatalities caused by diarrhoeal disease, the long term damage resulting from disease episodes is a significant cause for concern [1]. During the first two years of life, infants undergo a significant period of brain development and physical growth. If, during this critical period, children suffer from diarrhoeal diseases, episodes of which can occur repeatedly and are accompanied by impaired nutrient absorption, there is a significant risk that long term developmental disabilities might occur. Stunted growth (often by up to $8 \mathrm{~cm}$ at age 7), lower levels of physical fitness, and impaired cognitive function adversely impacting on academic performance can have serious implications in both adolescent and adult life [3]. Diarrhoeal diseases caused by pathogenic Escherichia coli, Vibrio cholerae and rotavirus have a particularly large global impact. However, a number of other enteric pathogens including Shigella dysenteriae, Salmonella enterica, Helicobacter pylori and Clostridium difficile are major causes of morbidity and mortality globally [4] and the development of effective non-living oral vaccines for these would be very desirable.

Enterotoxogenic Escherichia coli (ETEC) infections cause acute watery diarrhoea and are spread through the consumption of contaminated food and water. The global disease burden of ETEC is estimated at over 210 million cases and 380,000 deaths annually, mostly in children. ETEC is also a leading cause of Traveller's Diarrhoea in visitors to endemic regions. Recently, oral vaccine efforts against ETEC have focused on the generation of whole cell killed (WCK) bacteria expressing colonisation factor antigens (CFAs), a family of molecules that mediate the attachment of ETEC bacteria to intestinal epithelial cells (IECs), an essential step in pathogenesis $[5,6]$. Cholera is a severe diarrhoeal infection that continues to pose a major challenge globally and for which oral vaccination to induce toxin and lipopolysaccharide (LPS) specific secretory Immunoglobulin A (SIgA) responses is seen as the most appropriate vaccine strategy [5]. The diarrhoea caused by cholera however, is much more severe than ETEC, causing between 3-5 million cases and resulting in over 100,000 deaths annually. Disease outbreaks are frequent in endemic regions and often follow in the wake of natural disasters and conflict. Additionally, changes in global climate patterns are leading to increased disease outbreaks as pathogens find new environmental niches to occupy. Recently a correlation between the rise in the global burden of cholera and global warming due to climate change was proposed, indicating that future outbreaks may be more prevalent and may occur in previously unaffected regions [7]. The devastation resulting from the introduction of a diarrhoeal pathogen is exemplified by Haiti which experienced a cholera outbreak in the wake of the 2010 earthquake that was introduced to the country by United Nations (UN) relief soldiers from Tibet [8]. In such situations, oral vaccination is a quickly implementable strategy allowing for the containment and even prevention of such outbreaks [9-11]. Owing to this, oral vaccines have also generated interest as a frontline tool in biodefence against possible terrorist or biological weapon attack [12].

\subsection{Benefits of oral vaccines}

Since the development of the first vaccine against smallpox in 1796 by Edward Jenner [13], vaccines have made an enormous contribution to public health, most notably the global eradication of small pox by 1979 [14]. One of the greatest success stories of modern vaccine discovery was the development of an injectable polio vaccine (IPV) by Jonas Salk. IPV reduced the number of cases of polio in the United States from 35,000 in 1953 to 161 cases in 1961, a mere 6 years after its launch in 1955. Concurrently with Salk's efforts, a group led by Albert Sabin developed a live-attenuated oral polio virus vaccine (OPV). These efforts culminated in large scale clinical trials conducted within the Soviet Union in the 1950s which proved the safety and effectiveness of the OPV concept. These results led to the licensing of Sabin's OPV in 1962. The National Institute of Health launched a large scale OPV campaign in the United States in 1963, which largely replaced Salk's IPV vaccine due to the lower cost and ease of administration of OPV. In fact, up to 20 doses of OPV can be applied to sugar cubes and administered to children in the time it takes to load and administer a single dose of IPV, while the discomfort of receiving the injection is also circumvented. This was the first large scale demonstration of the benefits of oral vaccines versus traditional injectable vaccines. Despite its efficacy, OPV has been largely replaced by IPV in western vaccination schedules and OPV will be phased out globally over coming years in the interest of achieving a polio-free World. Polio virus has been documented in the stool of vaccinated individuals, possibly spreading infectious material [15]. This is likely due to shedding of the virus after non-disease causing 
Table 1

(Adapted from Lycke, N., 2012)

\begin{tabular}{|c|c|c|}
\hline Pathogen & $\begin{array}{l}\text { Commercial name } \\
\text { (manufacturer) }\end{array}$ & Components (dosing) \\
\hline Poliovirus & $\begin{array}{l}\text { Generally known } \\
\text { as OPV (Many) }\end{array}$ & $\begin{array}{l}\text { Trivalent, Bivalent and monovalent } \\
\text { live-attenuated vaccines ( } 3 \text { doses) }\end{array}$ \\
\hline Rotavirus & $\begin{array}{l}\text { RotaTeq } \\
\text { (Merck) }\end{array}$ & $\begin{array}{l}\text { Monovalent, live attenuated } \\
\text { ( } 3 \text { doses) }\end{array}$ \\
\hline Rotavirus & $\begin{array}{l}\text { Rotarix } \\
\text { (GSK) }\end{array}$ & $\begin{array}{l}\text { Multivalent reassortment } \\
\text { rotavirus } \\
\text { ( } 3 \text { doses) }\end{array}$ \\
\hline Salmonella typhi & $\begin{array}{l}\text { Vivotif } \\
\text { (Crucell) }\end{array}$ & $\begin{array}{l}\text { Live attenuated S. typhi ; Ty21A } \\
\text { (3-4 doses) }\end{array}$ \\
\hline Vibrio cholerae & $\begin{array}{l}\text { Dukoral } \\
\text { (Crucell) }\end{array}$ & $\begin{array}{l}\text { Whole killed } 01 \text { and El Tor biotype } \\
\text { V. cholerae and recombinant CTB } \\
\text { ( } 2-3 \text { doses) }\end{array}$ \\
\hline Vibrio cholerae & $\begin{array}{l}\text { Orochol } \\
\text { (Crucell) }\end{array}$ & $\begin{array}{l}\text { Live recombinant V.cholerae } \\
\text { mutant lacking CTA } \\
\text { (single dose) }\end{array}$ \\
\hline Vibrio cholerae & $\begin{array}{l}\text { mORC-Vax } \\
\text { (VaBiotech) }\end{array}$ & $\begin{array}{l}\text { Whole killed } 01,0139 \text { and } \\
\text { El Tor biotype V. cholerae } \\
\text { (2-3 doses) }\end{array}$ \\
\hline Vibrio cholerae & $\begin{array}{l}\text { Shanchol (Shantha } \\
\text { Biotechnics) }\end{array}$ & $\begin{array}{l}\text { Whole killed } 01,0139 \text { and } \\
\text { El Tor biotype V. cholerae } \\
\text { (2-3 doses) }\end{array}$ \\
\hline
\end{tabular}

colonization of the intestinal epithelium. However, of greater concern, $\mathrm{OPV}$ virus can in rare cases revert to a virulent form, causing latrogenic (vaccine-induced) polio [16].

Since Sabin's demonstration of the feasibility of the oral route for vaccine delivery, several oral vaccines against intestinal infections including cholera, rotavirus and salmonella have been licensed and put into use globally (Table 1 ). Oral vaccines are regarded as a highly advantageous alternative to injectable vaccines from a production, economic and regulatory perspective $[17,18]$. Regulatory requirements for oral products can be less stringent than for injectables, particularly relating to endotoxins [19]. Improved compliance and a reduced risk of adverse reactions are also commonly cited as additional benefits of oral vaccines. Economically, oral vaccines are best suited for mass-vaccination campaigns in poor regions as no needles are required, potentially enabling the option of self-administration. In addition to reducing the need for highly trained medical personnel to administer vaccines, this also avoids the risks of disease transmission through contaminated equipment $[20,21]$. If the oral route is to be an applicable solution for largescale vaccination with nonliving vaccines in resource-poor settings then addressing the challenge of maintaining the cold chain is a priority. Strategies to increase the temperature stability of vaccine components are required in parallel with innovative delivery strategies. In this context, the process of vitrification [22] to enhance stability is an attractive strategy, possibly combined with approaches such as gastric resistant microcapsules [23]. As with other oral delivery strategies it will be essential that the priorities of thermostabilisation and gastrointestinal delivery challenges are addressed in an integrated manner.

The vast majority of licenced vaccines are still administered via the parenteral route despite the fact that most pathogens enter the body via a mucosal tissue such as the lung or gastrointestinal tract (GIT) [24]. A significant potential advantage of oral vaccines is the induction of protective responses at the mucosal front line and systemically [25]. While systemic immunity is elicited by injectable vaccines, this strategy generally fails to elicit protective immune responses in the GIT. This is illustrated by the efficacy of both IPV and OPV, with the former protecting against the systemic manifestation of the disease, predominantly via IgG in the serum while OPV induces a local IgA response and prevents initial viral attachment to the epithelium and subsequent entry [26]. However a recent study shows that boosting with IPV can enhance mucosal immunity in those previously immunised with OPV [27]. Therefore in future oral prime/parenteral boost vaccine strategies may be considered.

\subsection{Challenges of developing new oral vaccines}

Despite sustained efforts to develop new oral vaccines, very few have been licensed in comparison to those targeted for injectable routes (Table 1). Many oral vaccines have shown promise in animal models but have later failed in clinical trials. However, live-attenuated vaccines against rotavirus and the causative agent of typhoid fever, $S$. enterica have been successfully used [28]. In the case of cholera, two WCK vaccines, Dukoral ${ }^{\circledR}$ and Shanchol ${ }^{\mathrm{TM}}$, have been licensed and are a proof of concept that non-living oral vaccines are feasible [28]. One drawback of many prototype WCK and subunit vaccines is suboptimal immunogenicity, requiring delivery strategies and the inclusion of immune-stimulatory adjuvants to drive enhanced innate and adaptive immunity [19]. A major challenge in this regard is that while a range of adjuvants have been included in licensed injectable vaccines, to date, none have been licenced for incorporation in oral vaccines. Despite these challenges, the logistical and immunological advantages of the oral route can out-weigh the challenges and there is renewed interest in the development of such vaccines in order to establish a protective immune response at the site of pathogen entry. Before one can begin to develop a candidate mucosal vaccine one must consider the complexity of the mucosal immune system which differs significantly from the systemic system.

\section{The oral route}

Oral delivery has long been the preferred means of drug administration as the intestinal epithelium is highly absorptive with an incredibly large surface area, encompassing some $300-400 \mathrm{~m}^{2}$ [29]. The constituent lymphoid tissue, referred to as the gut associated mucosal tissue (GALT) is categorised in terms of inductive sites where immune responses are initiated and effector sites where adaptive immune responses are manifested and executed (Fig. 1). However, despite the advantages of the oral route and the relative ease with which many drugs can be delivered to intestinal tissues, the delivery of oral vaccines is faced with unique and significant challenges. Among the many obstacles to oral vaccine delivery, particularly for subunit vaccines, are poor stability in the GIT due to low gastric $\mathrm{pH}$, digestive enzymes, dilution, dispersal and the mucus barrier. In order to overcome these challenges, it is necessary to design delivery systems to protect and aid in the delivery of oral vaccine formulations to immune inductive sites.

\subsection{Physical and chemical barriers}

When developing oral vaccines one must consider the physiochemical barriers which constitute the frontline defences against enteric pathogens. Under normal physiological conditions these can prevent colonisation of the intestinal epithelium by potentially invasive pathogens and maintain symbiotic interactions with the microflora but pose significant challenges for the effective delivery of orally administered vaccines. Comprising a hydrogel with incorporated components including proteins, carbohydrates, lipids, salts, antibodies, cellular debris and bacteria, mucus forms a highly viscous and heterogeneous microenvironment [30]. The viscoelastic properties of mucus are dependent on mucins, a diverse family of heavily glycosylated proteins $[31,32]$. The relative thickness of mucus varies greatly along the length of the GIT averaging $170 \mu \mathrm{m}$ in the stomach; providing protection against stomach acids, $10 \mu \mathrm{m}$ in the ileum and $100 \mu \mathrm{m}$ in the large intestine which is heavily colonised by commensal bacteria $[33,34]$. The loosely adherent mucus layer is constantly removed by peristalsis and thus has an extremely high turnover [32] although in the colon an underlying firmly adherent mucus layer is present. Viruses may be trapped by hydrophobic and electrostatic interactions with mucin fibres [35]. Mucus characteristics have significant design implications when it comes to WCK vaccines, for example charged molecules may be repelled or become attached to the mucus, potentially enhancing proteolysis and clearance 


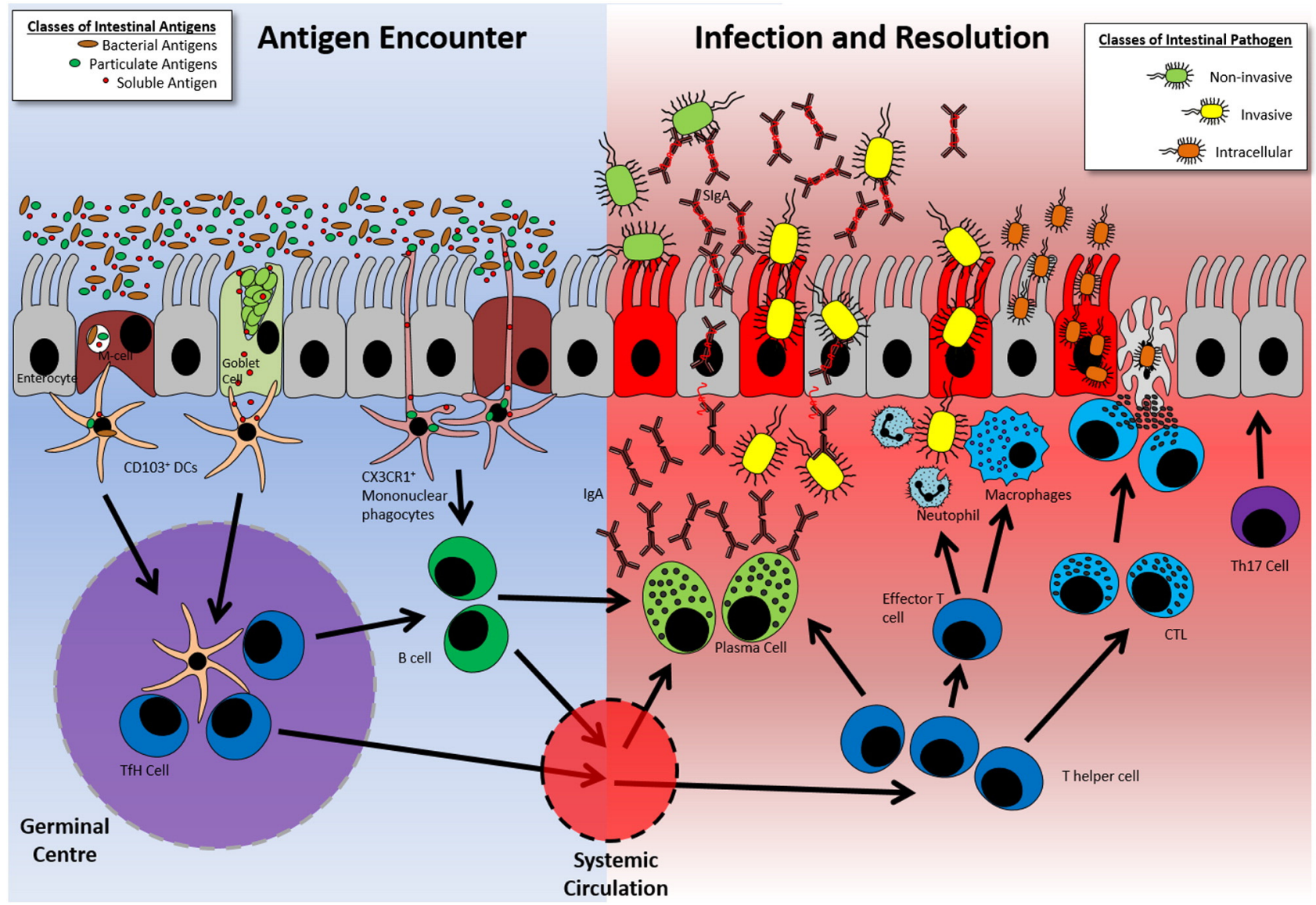

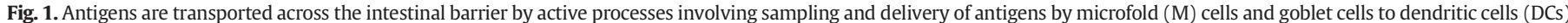

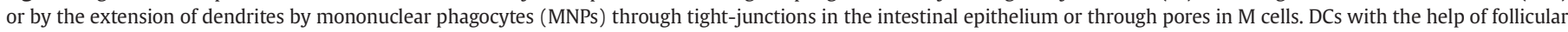

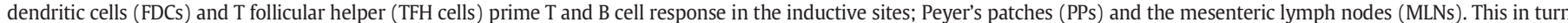

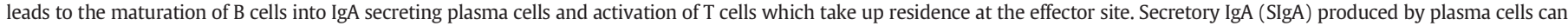

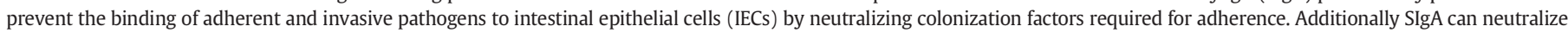

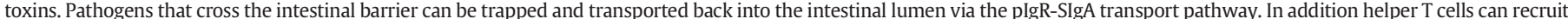

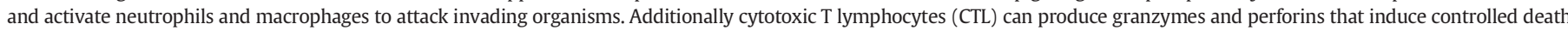

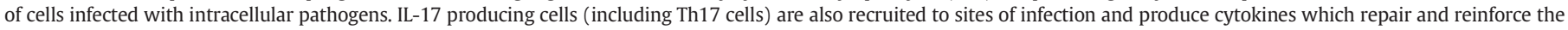
intestinal epithelial barrier in addition to promoting the production of and secretion of other anti-microbial factors and SIgA.

[36]. Strategies to achieve site-specific vaccine delivery must take into account the significant differences in the nature and thickness of mucus present at specific gastrointestinal sites. Small intestinal mucus was penetrable by polystyrene beads of $0.5-2 \mu \mathrm{m}$ in size while the inner colonic mucus layer was impenetrable to these particles [37]. Penetration enhancers and mucolytic agents may have potential to address the challenge of the mucus barrier particularly in the large intestine [33]. A further challenge is the large volumes of liquid in the intestine (approximately $10 \mathrm{~L}$ of water per day into the adult GIT) which can lead to significant dilution of vaccine components and inefficient delivery to immune inductive sites [36].

Gastrointestinal chemical and enzymatic barriers in the upper digestive tract, stomach and intestine also pose considerable risks to the integrity of delivery systems and labile vaccine components. Lysozyme, phospholipase A and other enzymes found in the saliva can act on peptides or peptidoglycan at the point of entry for vaccines in the oral cavity. The acidic gastric environment ( $\mathrm{pH} 1-2)$ together with pepsin presents a particularly harsh environment, which is exacerbated by prolonged gastric residency times in humans. Differences in the chemical composition of gastric secretions and stomach residency times varies between species can complicate translation of vaccine findings from small animal models into humans [38]. High concentrations of intestinal proteases can degrade protein and peptide based subunit vaccines, while, bile salts and acids such as deoxycholic acid (DCA) and chenodeoxycholic acid (CDCA) are a further challenge in the case of lipid antigens and lipid based delivery systems.

Targeting cells involved in active antigen sampling is essential since uptake of macromolecules and particulates by and between IECs is very limited [34] Therefore combined strategies to address the physical and chemical challenges and direct vaccines to the key immune inductive sites are required. Since the main intestinal immune inductive sites, Peyer's patches (PPs) are more abundant in the ileum compared to the duodenum and jejunum [34] targeting vaccines, especially particulate formulations to this area is a priority. Additional GALT inductive sites that offer targets for targeted oral vaccine delivery include caecal and colonic patches [34].

\subsection{Poor mucosal immunogenicity (hypo-responsiveness and tolerance)}

A key challenge when vaccinating orally is the inherent predisposition towards tolerance and hypo-responsiveness by the immune system in the gut. The immunogenicity of many antigens including heat killed bacteria following oral delivery is lower than after injection. This may be partially due to the potential to accurately inject the pre-formulated vaccine into a discrete site in the muscle or under the skin compared to the dispersal and degradation of oral vaccine components in the GIT. Therefore, it is generally necessary to incorporate a mucosal adjuvant into the vaccine formulation in order to overcome these challenges, 
although none have been licensed for oral vaccines to date [36]. A consistent trend has been observed where candidate oral vaccines often perform less effectively in subjects during field trials in endemic areas of developing countries when compared to subjects from developed nations [39]. This phenomenon is known as the "Tropical Barrier" and may have several underlying causes [19]. Preliminary work in rodents has identified vitamin A deficiency, which is common in developing countries, likely a result of malnutrition, as a contributing factor in the reduced capacity of such individuals to mount a mucosal immune response [40]. Additional factors such as previous exposure to antigens, microbiota composition and parasite infections can also influence the capacity of the intestinal immune system to mount effector and memory responses against oral vaccines $[19,41]$.

\section{Immune Responses to enteric infections}

\subsection{Antigen uptake in the gut}

Multiple mechanisms of intestinal antigen uptake exist to sample and deliver luminal antigens to antigen-presenting cells (APCs) which then migrate to the major inductive sites of the intestine, namely the PPs and the mesenteric lymph nodes (MLNs) (Fig. 1). Several processes of antigen uptake have been identified including direct sampling by mononuclear phagocytes (MNPs) [42,43], specialised IECs called microfold $(M)$ cells $[44,45]$ and mucus secreting goblet cells [46] (Fig. 1). The nature of the antigen strongly influences the mechanism of uptake with $\mathrm{M}$ cells playing a decisive role in the case of particulates and large antigens. This is a key issue in vaccine design since the efficiency of $\mathrm{M}$ cells at sampling luminal antigen makes them a prime target to enhance oral vaccine efficacy. These cells differ from other IECs which function primarily as absorptive enterocytes, specialized for nutrient uptake [47].

$M$ cells differ significantly from enterocytes in terms of the brush border and surface glycocalyx layer, thus allowing effective internalisation of particulate antigens, bacteria and viruses [48]. Following uptake, antigens can be delivered by transcytosis to underlying dendritic cells (DCs), via direct contact in the basolateral pocket directly below the M cell [49] (Fig. 1). The relative abundance of $M$ cells at the primary inductive sites of mucosal immune responses particularly the PPs, makes these an attractive site for oral vaccine delivery [48]. However, of the specialised follicle associated epithelium (FAE), M cells only constitute approximately $10 \%$ in mice [48] while in humans this figure is less than 5\% [50]. PPs are built on a stromal cell (SC) scaffold, rich in APCs including a number of DC subsets. It is also in these tissues and the draining MLNs that isotype switching, differentiation of B cells to plasma cells and imprinting of gut homing on lymphocytes occurs [51, 52] (Fig. 1). The area of the PP below the M cell is referred to as the basolateral pocket and contains a heterogeneous population of lymphocytes, macrophages and DCs. This microenvironment is highly conducive to antigen translocation and encounter with APCs. Studies have demonstrated that in the absence of $M$ cells, antigen-specific T cell responses are compromised demonstrating their pivotal role in the induction of mucosal adaptive immune responses [53-55]. M cell development is thought to occur from the differentiation of epithelial stem cells in the crypts (see Mabbott et al., 2013 for an excellent review of $M$ cell development, characterisation and function in the intestine). Epithelial cells can produce the chemokine CCL20 in response to flagellated bacterial pathogens including $S$. typhimurium, S. enteritidis and L. monocytogenes, leading to the recruitment of DCs and lymphocytes [56]. In the absence of CCR6, the cognate receptor for CCL20, M cell differentiation was compromised [57-59]. A subset of CCR6 +, CD11c-expressing $B$ cells have been shown to be recruited to the FAE and promotes $M$ cell differentiation [57]. Although it is hypothesized that this may be a bacterial pathogenecity mechanism to enhance uptake via the recruitment of CCR6-expressing cells to upregulate $M$ cell numbers [48], the pathway may also serve as a novel strategy to enhance $M$ cell numbers in the GIT prior to oral vaccine delivery. While M cells constitutively sample luminal antigens, the expression of ligand-specific apical receptors suggests their capacity to take up materials selectively, potentially providing novel targets for vaccine delivery. These receptors include glycoprotein 2 (GP2) which binds the FimH component of type 1 pili on the surface of both commensal (E. coli) and pathogenic bacteria (S. typhimurium) [53]. Annexin A5, a receptor expressed on the apical side of $M$ cells has been shown to bind to the lipid A domain of the LPS molecule found on gram-negative bacteria [60]. LPS antigens have been shown to be protective in the case of the oral cholera vaccine [5], and so targeting such receptors may offer a novel approach to enhance the uptake of LPSbased antigens. SIgA is the main Ig isotype associated with gut immune responses and has also been implicated in the transport of antigens from the lumen of the gut across the epithelium $[61,62]$. SIgA containing complexes have been shown to be transcytosed through M cells to APCs and lymphocytes in the subepithelial dome (SED) [61,62]. Although no specific apical receptor for SIgA complexes has been described, Dectin-1 has been implicated as an important player in this process [63]. Therefore exploiting S-IgA specific epithelial receptors may offer opportunities to enhance antigen uptake following oral delivery.

In addition to PPs, caecal and colonic patches in addition to isolated lymphoid follicles (ILFs) throughout the intestinal tract may constitute inductive sites that can be productively targeted for oral vaccine delivery. While similar in some respects to peripheral lymph nodes, this organized lymphoid tissue contains a higher proportion of $B$ cells to $T$ cells. As in the case of PPs, a follicle associated epithelium with M cells is present on the lumen facing side of ILFs. Uptake of pathogens including S. typhimurium, leads to the formation of germinal centers (GCs) in mature ILFs [64-66]. Interestingly, it was found that the presence or absence of GCs in ILFs did not influence the active class switching of naïve B cells to active IgA secreting B cells [67]. This study also found that unlike in PPS, the ILFs were a major site of T cell independent induction and generation of IgA secreting plasma cells [67].

\subsection{Gut immune responses}

The majority of activated lymphocytes in PPs reside in GCs, specialized micro-environments facilitating interactions between $\mathrm{T}$ and $\mathrm{B}$ cells and resident follicular dendritic cells (FDCs). FDCs are assisted by a specialized $\mathrm{T}$ helper cell subset called follicular helper T cells (TFH) [68]. Together the FDCs and TFH cells efficiently supply conditions that are conducive to efficient class switching and differentiation of naïve $B$ cells into IgA secreting plasma cells, antigen presentation and T-B cell interactions (Fig. 1). Resident DCs play a determining role in the induction of local adaptive immune responses so resolving which DC subsets regulate specific responses and how is a priority in vaccine research. $\mathrm{CD}_{103^{+}}$DCs promote IgA-producing $B$ cell responses in the PP and can also migrate to the MLNs where they can initiate preferential class switch recombination (CSR) to IgA in B cells [69]. T cells resident in the PPs and MLNs are also educated by gut DCs to produce cytokines that are conducive to B cell class switching [70-72] (Fig. 1).

While both DCs and MNPs have been shown to internalise and present antigen, only $\mathrm{CD} 103^{+}$intestinal DCs have the ability to imprint a gut homing phenotype on lymphocytes $[73,74]$. Specific targeting of CD103 ${ }^{+}$DCs was shown to stimulate effective mucosal homing of activated T cells [75]. This is thought to be the reason why vaccine administration at sites other than the mucosa is generally ineffective at promoting mucosal immunity [36]. The imprinting of gut homing molecules on lymphocytes by DCs is dependent on retinoic acid [76-78]. Upon antigen encounter, $C D 103^{+}$DCs undergo maturation which allows them to migrate to the MLNs, initiating adaptive immune responses [73] (Fig. 1). Thus specific DC populations and local factors result in preferential generation of IgA-producing B cells in the GALT and MLNs and imprinting of lymphocytes with the specific gut homing receptors $\alpha 4 \beta 7$ integrin, CCR9 and CCR10 [66,71]. In support of the idea of a common mucosal immune system, lung DCs have also been shown to be capable of imprinting a GIT homing phenotype on $T$ cells allowing for their migration to the gut 
where they facilitated protection against an intestinal Salmonella infection [79].

Once primed, lymphocytes exit the PPs and the MLNs via the thoracic duct and blood and finally migrate back to the gut via homing receptors and cognate ligands expressed only in the gut tissue. The integrin $\alpha 4 \beta 7$ allows lymphocytes to specifically attach to the mucosal addressin, cell adhesion molecule-1 (MADCAM-1) [74,80] expressed on endothelial cells of the post capillary venules in the gut lamina propria (LP) thus guiding lymphocytes toward these key gut effector sites [66]. The chemokine receptors CCR9 and CCR10 allow lymphocyte homing to the small or large intestine where endothelial cells produce CCL25 and CCL28 respectively, adding further gut homing specificity $[81,82]$. Effector responses can consequently be manifested in the LP or between epithelial cells in the case of intra-epithelial lymphocytes (IELs) [83-85]. The desired outcome of oral vaccination against diarrhoeal infections is the reinforcement of gut barriers through SIgA antibodies $[25,86]$ and effector/memory $\mathrm{T}$ and $\mathrm{B}$ cells which enhance frontline defences against pathogen reencounter $[83,87]$. Other local responses against gut infections include the augmented secretion of host factors such as defensins, cytokines and chemokines [88,89].

\subsection{Protective responses against enteric pathogens}

IgA is the dominant antibody class present in intestinal secretions and breast milk, conferring passive immunity to breast feeding infants. It can be found in monomeric or dimeric form, composed of two IgA monomers linked by a J chain. IgA acts at mucosal membranes to agglutinate and neutralize antigens, trapping them in the mucus, which can then be expelled (Fig. 1). On the other hand, IgG, the most abundant antibody class present in the serum and tissue fluids, promotes opsonisation, neutralization and agglutination of antigens as well as complement activation. It can also cross the placenta, thus inducing passive immunity in the foetus.

The GIT produces IgA in kilogram quantities annually [90]. Produced by plasma cells in the LP of the intestine as a dimer, the IgA binds to the polymeric Ig receptor ( $\mathrm{pIgR}$ ) located on the basal side of the intestinal epithelium which then, via an active mechanism, transports the IgA molecule through the epithelial cell across into the intestinal lumen [91] (Fig. 1). SIgA forms a critical part of the intestinal immune system both in protection from harmful pathogens and in homeostasis [91]. It is especially suited to its role in the intestinal immune system as SIgA is highly protease resistant [92]. SIgA exerts its functions in defence against pathogens by neutralizing bacterial toxins, blocking adhesion molecules expressed by pathogens and transporting antigens and pathogens out of the LP back into the gut lumen [93] (Fig. 1). SIgA secreted into the lumen of the intestine functions by limiting direct contact of both commensal and pathogenic bacteria and viruses with the gut epithelium, and together with other anti-microbial factors generates a "no go zone" [94]. Interestingly commensal bacteria have been shown to stimulate antigen specific IgA production, albeit of lower affinity than pathogen-associated IgA responses [95]. Recently a study demonstrated that IgA-coated commensal bacteria isolated from inflammatory bowel disease (IBD) patients led to the establishment of IBD in germ-free mice suggesting that more pro-inflammatory commensals drive SIgA responses with higher affinities [96].

Since SIgA has been shown to limit the penetration of colonizing bacteria in the intestine [69,97] its induction as an anti-toxin or anti-colonisation strategy can be highly effective. Kiyono et al. demonstrated that protection against experimental enteric cholera toxin (CT) challenge following oral vaccination was dependent on SIgA [98]. pIgR was required for vaccine-mediated protection against oral $C T$ and heat labile toxin from E. coli (LT). Moreover, intestinal SIgA antibodies against the B subunit of CT (CTB) are known correlates of oral vaccine efficacy in humans and SIgA against bacterial colonisation factors has been established as one of the key mediators of intestinal immunity to ETEC infections [99]. Thus SigA can act in the exclusion and excretion of antigens in addition to potentially enhancing local immune responses by targeting antigens specifically to M cells [62].

\section{Oral vaccine components}

\subsection{Classes of mucosal antigen}

The current licenced oral vaccines are either composed of liveattenuated organisms or WCK bacteria either alone or in combination with protein subunit components (Table 1 ). Live-attenuated vaccines can be highly effective as they establish a limited local infection, thus contributing many intrinsic immune-activating signals. However, there can be safety concerns associated with some of these vaccines, particularly in immunocompromised individuals [100]. While live attenuated vaccines will continue to play a role in global vaccine efforts, there is a move towards non-living, subunit vaccines or enhanced WCK approaches both from a safety and cost perspective [28].

The over-expression of ETEC antigens by non-pathogenic E. coli is one strategy which has delivered promising pre-clinical and phase I human trial results [101-103]. Additionally, novel strains of $V$. cholerae expressing multiple surface antigens have been generated and hold promise for future trials [104]. The use of WCK genetically modified non-pathogenic bacteria as antigen vectors may improve safety and ease of production while enhancing antigenicity.

In an alternative approach, outer membrane vesicles (OMVs) derived from Burkholderia pseudomallei have been demonstrated to be safe, non-replicating and immunogenic following intra-nasal immunisation [105]. Early studies in nonhuman primates have also demonstrated the potential of B. pseudomallei OMVs as novel antigens [106]. Several other bacteria-derived OMV-based antigens are also in development, while an OMV-based vaccine against Nesseria meningitidis has been licensed for (injectable) use in humans [107]. Anthrax spores have also been evaluated by the nasal route and successfully protected against challenge following vaccination [108]. The potential of these systems for oral vaccination is less clear but their efficacy could be enhanced by capsule based approaches with incorporated adjuvants. Other strategies that may offer potential include the expression of pathogen-derived antigens on live lactic acid bacteria (Lactobacillus casei and L. lactis) [109] and virus-like particles (VLPS) [110]. Components of toxins and toxoids have also been used to provide anti-toxic immunity. This is best demonstrated by the CTB component of the oral cholera vaccine Dukoral ${ }^{\circledR}$ which successfully protects against both $C T$ and $L T$ induced diarrhea for up to 6 months [99]. It has been suggested that CTB acts in synergy with WCK V. cholerae, enhancing immunity against both components [99]. However, Dukoral ${ }^{\circ}$ is an exception to the rule for many subunit vaccines have been tested and failed [36]. This could be due to the high immunogenicity of $C T B$, its ability to bind to the ganglioside receptor monosialotetrahexosylganglioside (GM1) and enter nucleated cells and its intrinsic immunomodulatory capacity [111] as well as the presence of heat killed bacteria. Regardless of the type of non-living antigen, in most cases immunogenicity is not sufficient when these are administered alone, necessitating delivery systems and adjuvants to enhance adaptive immunity.

A considerable challenge to developing new mucosal antigens is the requirement for their production under good manufacturing practise (GMP). A Vietnamese oral cholera vaccine ORCVAX® could not be licensed for use by the World Health Organization due to production issues not complying with GMP conditions [112]. These issues were however later addressed by the production of the ORCVAX® formulation in India by Shantha Biotechnics under GMP conditions and it is marketed under the trade name Shanchol ${ }^{\circledR}$. Therefore the ability to produce a vaccine under GMP is an important early consideration to make and one that is exemplified by the current oral ETEC vaccine candidate undergoing clinical trials where all components are produced under GMP [101]. 


\subsection{Mucosal adjuvants}

While several adjuvants have been developed to improve the immunogenicity of injectable non-living vaccines, these are lacking for the oral route. The most potent category of mucosal adjuvants identified to date are those based on the bacterial enterotoxins, CT and LT. These toxins share significant sequence homology [113] and are complexes composed of an ADP-ribosylating A1 (active) subunit connected to a donut shaped pentamer of $B$ (binding) subunits joined by an A2 linked chain [114]. Following binding to GM1 and internalisation, the A1 subunit of the holotoxin mediates a cascade of intracellular events, culminating in the ADP-ribosylation-mediated increase in the cytoplasmic level of cyclic adenosine monophosphate (cAMP) a feature also associated with osmotic diarrhoea during infection [115]. The adjuvanticity of CT and LT is thought to involve both enhanced permeation of antigens across mucosal epithelial barriers and an increase in antigen presentation and activation of APCs $[99,116]$. Enhanced M cell targeting is also observed in vaccines adjuvanted with LT and CT [25]. CTB was shown to promote DC-driven induction of IgA producing B cells by DCs [117], which may account for its use as an immunotherapeutic adjuvant [118] although the induction of potent antibody responses against orally delivered CTB generally requires the addition of a potent adjuvant. Due to the high level of structural and sequence homology between CT and LT, it is plausible to speculate that both toxins exert their adjuvant effects by identical or highly similar mechanisms. Unfortunately, despite their efficacy in pre-clinical studies these molecules are too toxic in their native form for use in humans. When a nasal VLP-based influenza vaccine adjuvanted with LT was tested in humans, several individuals developed Bell's Palsy (facial paralysis) as a result of LT interacting with GM1 on nerve cells [119-121]. Additionally microgram amounts of CT and LT cause profuse diarrhoea in humans thus making them unsuitable for the oral route [36].

This led to the generation of toxin mutants with attenuated enzymatic activity by site directed mutations in the A1 subunit [122]. Site-directed mutagenesis of LT led to the generation of potent mutant toxin adjuvants which appeared safer than their native counterparts. LTK63 and LTR72, developed by Novartis, contain single amino acid mutations that abolishes or significantly reduces their ADP-ribosylating activity respectively while maintaining their ability to elicit immune responses [123]. In preclinical intranasal studies, whole cell mucosal vaccines adjuvanted with LT mutants led to protection against challenge with the mucosal pathogens Bordetella pertussis [124] and Streptococcus pneumoniae [125]. Additionally, oral and intranasal administration of a human immunodeficiency virus (HIV)-1 p55 gag subunit vaccine adjuvanted with LT mutants elicited strong cytotoxic T cell responses [126]. However, when tested in clinical trials, despite lacking all enzymatic activity [123], Bell's Palsy was documented in a small number of patients receiving an LTK63 adjuvanted intranasal vaccine [36]. This led to regulatory authorities cautioning against the intranasal use of GM1 binding adjuvants [127] although these molecules may still hold significant promise as oral adjuvants where they can exhibit unique potency. Recently a double mutant LT (dmLT) was developed [128], having greater stability in the presence of trypsin, strong oral adjuvant properties [129] and an acceptable enterotoxicity profile, even at high doses, and is currently being assessed as part of a prototype oral ETEC vaccine in clinical trials [130].

Another strategy to overcome the issues associated with toxicity was adopted by Nils Lycke's group to develop a non-toxic CT derivative. This unique adjuvant is a fusion protein composed of the A subunit of CT (CTA) which retains $100 \%$ of its enzymatic activity and the dimer of the D-fragment of the Staphylococcus aureus protein A to form the adjuvant CTA1-DD [131]. CTA1-DD has been shown to enhance the immunogenicity of a number of different vaccine antigens [132]. By exclusively using the CTA portion of CT, CTA1-DD is also unable to bind to GM1 which has greatly enhanced its safety, and no side effects were observed in tests in animal models and non-human primates following nasal administration $[133,134]$ although oral delivery of this adjuvant has received less attention.

Recently populations of unconventional $\mathrm{T}$ cells have attracted interest as possible adjuvant targets for mucosal vaccination. Their localisation at mucosal sites, immune-modulating capacity and the availability of known ligands for both invariant natural killer (iNKT) cells and mucosal-associated invariant T (MAIT) cells has attracted interest in targeting these cells to potentiate immune responses to orally delivered antigens $[135,136]$. Another novel oral adjuvant strategy has been the administration of live bacterial adjuvants such as Bacillus Calmette-Guérin (BCG), Lactobacillus plantarum or L. rhamnosus together with inactivated simian immunodeficiency virus (SIV). This led to the protection of macaques against intra-rectal SIV challenge, albeit by a novel means of tolerance induction rather than antibody or cytotoxic lymphocyte (CTL)-mediated protection [137].

\section{Oral vaccine delivery systems}

\subsection{Lipid based delivery systems: emulsions, liposomes and ISCOMs}

Some of the earliest adjuvants and delivery systems developed took the form of lipid-in-water or water-in-lipid emulsions such as Freund's incomplete adjuvant (Fig. 2C\&D). Emulsions have been extensively tested in various human trials, leading to the licensing of systems including MF59; an oil-in-water emulsion containing squalene that drives humoral immunity and CD4 + T memory cells [138]. Micelles are one of the earliest examples of utilizing lipids as delivery vehicles and consist of amphiphilic block copolymers displaying both hydrophobic and hydrophilic segments which allows for differences in solubility. These unique properties drive their self-assembly into core-shell architectures which then allows for a payload to be delivered inside the core or attached on the outside to the shell depending on the electrochemical properties of the vaccine formulation [139]. However, micelles can often dissociate when diluted, leading to loss of the payload. Newer polymers allow for the intentional release of a payload in a controlled-release fashion. Micelles can also be synthesized in the nano-meter range, allowing for the engineering of delivery vehicles that can potentially penetrate mucus and be taken up by mucosal antigen presenting cells.

\subsubsection{Liposomes}

While micelles are composed of lipid monolayers, liposomes are characterized by a single or collection of multiple phospholipid bilayers surrounding an aqueous core [140]. This structure grants liposomes the ability to be tailored to suit a large variety of different applications (Fig. 2F). While currently no liposome-based systems are licensed for human use, several are in various stages of clinical trials. AS01 developed by GlaxoSmithKline, is liposome-based and includes the toll-like receptor (TLR)-4 agonist MPL and the purified QS21 fraction of Quil A saponin. This adjuvant is a vaccine component in an ongoing phase III malaria trial [141,142]. While most clinical trials involving liposomes have focused on the intra muscular route, there is some evidence to support their use as mucosal delivery systems [143].

An important determinant of the adjuvanticity of liposomes has been shown to be the surface charge on the vesicle. This is determined by the chemical properties of different phospholipids with charged head groups (Fig. 2F). Positively charged (cationic) liposomes have been demonstrated to possess the strongest adjuvanticity compared to neutral and negatively charged liposomes [144]. This is likely due to the overall negative charge (anionic) of most cell membranes resulting in interactions with the cationic liposomes, which may explain the enhancement of antigen uptake [145]. However, a concern is the greater toxicity of cationic than anionic liposomes. Recently a study was conducted into the mechanisms of toxicity of cationic liposomes and carriers, reporting that cationic delivery vehicles induce necrosis, the release of damage-associated molecular patterns (DAMPs) and inflammation in vivo [146]. However these effects are likely to be highly dose 


\section{Different oral vaccine delivery strategies}

A. Solution

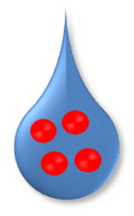

B. Virus-like particle

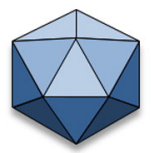

C. Water-in-Oil

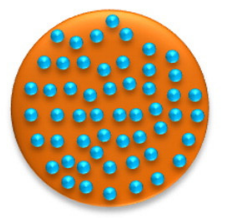

D. Oil-in-Water

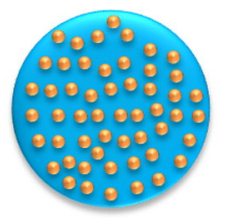

E. ISCOM

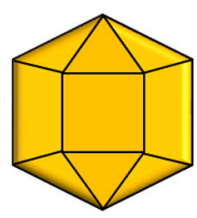

F. Liposome

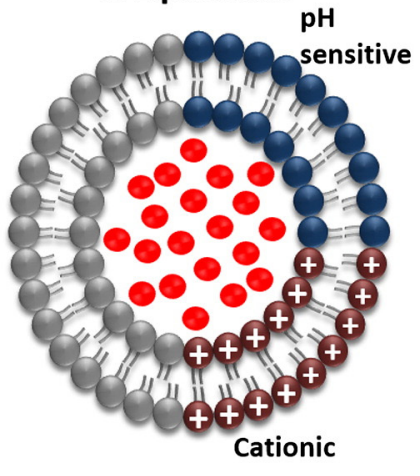

G. Particle-based

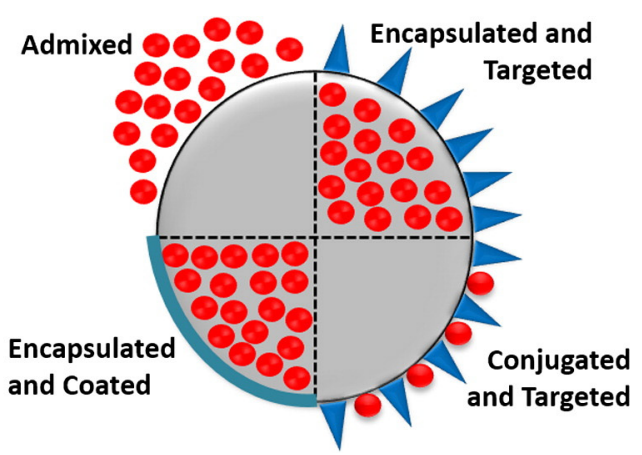

H. Capsule

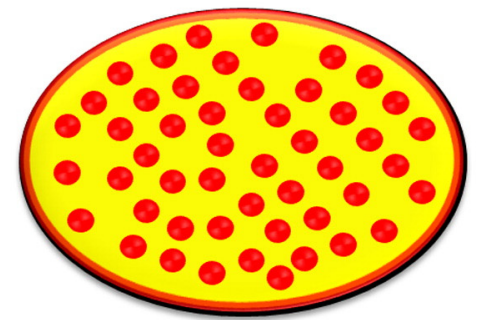

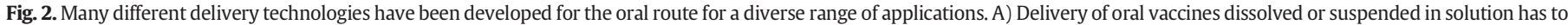

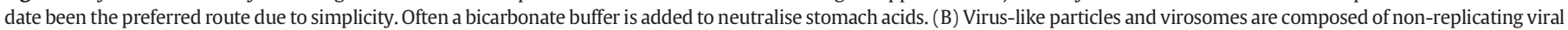

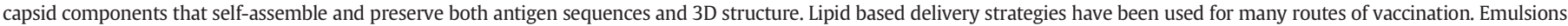

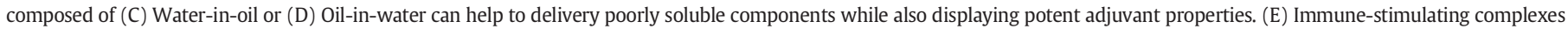

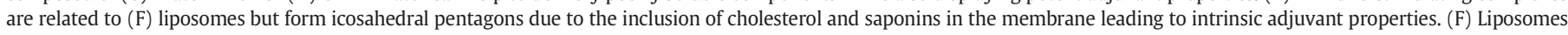

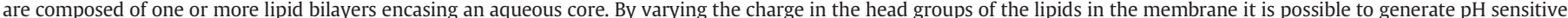

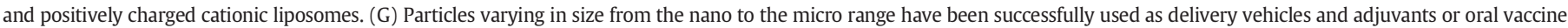

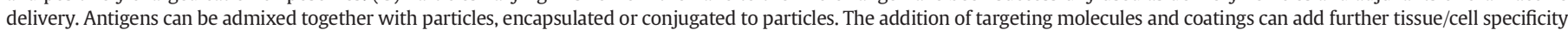

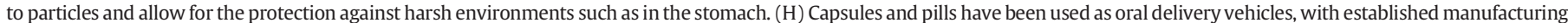

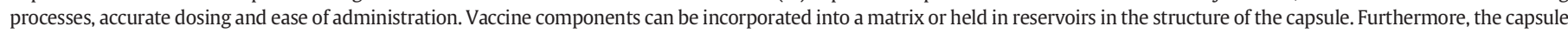
approach allows for the incorporation of the other delivery systems outlined above (A-G) into a large delivery vehicle.

and route dependent. Many peptide and protein antigens are anionic, thus allowing for the exploitation of electrostatic associations in the association and loading of antigens. CAF01 is an example of a cationic liposome that has been shown to enhance cellular immunity against Tuberculosis (TB), HIV, chlamydia and malaria antigens [147-150]. Interestingly, CAF01 was shown to be a highly effective adjuvant/delivery system for intra-nasal administration of vaccines. Co-delivery of CAF01 with the influenza vaccine Vaxigrip ${ }^{\circledR}$ led to enhanced systemic $\operatorname{IgG}$ and Th1 responses in mice [151]. Furthermore, intra-nasal vaccination with cationic liposomes enhanced mucosal IgA and systemic IgG responses together with potent cell-mediated immune responses but most importantly protection against lethal infection following the delivery of a DNA vaccine against B. pseudomallei [152]. The natural hydrophobicity of liposomes endows them with the ability to fuse with target cell membranes, allowing for direct delivery of antigens into the cytosol and trafficking to the major histocompatibility complex (MHC) class I presentation machinery. Such fusogenic liposomes have been shown to stimulate cell mediated immunity and are capable of augmenting $\mathrm{CD} 8^{+} \mathrm{T}$ cell responses to vaccine antigens $[153,154]$.

While the efficacy of liposomes has been extensively demonstrated for the injectable and more recently the intra-nasal route, their use orally is more limited. As with emulsions and micelles, liposomes are susceptible to degradation in the GIT through acidic $\mathrm{pH}$, lipases and bile salts. Bile salts such as CDCA and DCA are secreted into the GIT to digest lipids making it unlikely that liposomes would retain their structural integrity in such an environment, thus compromising their ability to protect antigens and potentiate immune responses long enough to reach inductive sites in the gut. One strategy to enhance oral efficacy was the use of lectin bearing polymerized liposomes [155] with increased gastrointestinal stability. Additionally, attempts to coat liposomes with polymers to protect them from degradation in the GIT has yielded some success in mouse models [156] but the potential of this technology remains to be extensively evaluated.

\subsubsection{Immune-stimulating complexes}

The addition of cholesterol and saponins; most commonly Quil A to liposomes results in the generation of self-assembling pentagonal dodecahedrons. The incorporation of these additional components confers intrinsic adjuvant properties earning their name as immunestimulating complexes (ISCOMs) (Fig. 2E). ISCOMs were developed in the 1980 s and can be considered a second generation liposome in many regards [157]. Two variants of ISCOMs exist with the first "classical" variety containing entrapped protein antigens of either viral or bacterial origin allowing them to act as both a delivery and adjuvant system. The second variety, referred to as ISCOM matrices, contain no entrapped antigens and are utilized as a co-delivered adjuvant more so than a delivery system. Early ISCOM formulations could not be evaluated in humans due to the reactogenicity of Quil A. QS21 is now commonly tested alone in vaccine formulations and within ISCOMs due to its improved safety profile while still remaining active as an adjuvant $[158,159]$. One major challenge when working with ISCOMs is the 
difficulty associated with antigen incorporation. ISCOMs are negatively charged and so cannot interact with negatively charged protein subunit antigens. The development of PLUSCOMS and Posintro ${ }^{\mathrm{TM}}$ has been successful in altering the surface charge of the particle [160,161]. The incorporation of positively charged cholesterol derivatives led to the induction of potent immune responses following vaccination with hepatitis B (HepB) surface antigen [161]. These modifications allow the incorporation of hydrophilic antigens with greater ease in contrast to hydrophobic antigens as was the case with classical ISCOMs. However, several trials have suggested that ISCOM matrices used purely as adjuvants may be just as beneficial at eliciting immune responses as classical or charge-modified ISCOMs [162]. The use of unmodified ISCOMs as adjuvants would significantly simplify production, however the benefit of antigen encapsulation would also be lost, which for the oral route is an important key to success. ISCOMs containing diphtheria toxin were capable of priming both humoral and systemic responses following injection [163] but neutralizing antibody responses in the serum and intestinal IgA responses were limited following oral administration [163]. These results suggest that to improve the oral efficacy of ISCOMs a modification of the immunization protocol such as including an oral/injectable prime-boost regimen or the use of additional coatings or adjuvants may improve efficacy. The inclusion of the mucosal adjuvant CTA1-DD did enhance the ability of nasally delivered ISCOMs to enhance immune responses [164], suggesting that the addition of an additional immune stimulatory component may serve to potentiate the oral efficacy of ISCOMs.

\subsection{Virus-like particles}

VLPs have delivered more licensed vaccines with less expenditure than adjuvanted subunit antigens, begging the question as to whether particulate antigen presentation should be the key focus for non-living vaccines [165]. Their intrinsic antigenicity coupled with the ease of their manufacture has attracted a significant degree of interest [165-167]. VLPs make for a very practical alternative to traditional live-attenuated viral antigens in that they consist of a self-assembling 3D viral envelope complex similar to their native virus $[165,167]$. These 3D structures maintain not only the unique peptide sequence of the antigen, but also the antigenic structure (Fig. 2B). Additionally, this multimeric complex lacks any viral RNA/DNA and is therefore incapable of replication [168]. Moreover, VLPs can be expressed with additional antigens on or, in the case of polysaccharide or lipid molecules, conjugated to the surface to create a multivalent vaccine [166, 169-171]. VLPs contain one or more viral capsid proteins which make up the protective outer shell of a virion and are usually expressed in a eukaryotic cell [110]. An example of a clinically and commercially viable VLP vaccine is the HepB vaccine [110], a product of the self-assembly of HepB surface antigen expressed in recombinant yeast cells [165]. Another licensed VLP vaccine is the human papillomavirus (HPV) vaccine which was also the first prophylactic vaccine against a carcinogen [165]. Produced by Merk \& Co, Gardasil ${ }^{\circledR}$ is a self-assembling VLP providing quadrivalent protection against genitournial HPV infection. It is composed of the L1 capsid protein of HPV-6, $-11,-16$ and -18 types expressed by recombinant yeast cells [172]. Interestingly, this vaccine, which is administered in adolescents via injection, elicits strong protection at genital mucosal surfaces via neutralizing serum IgG production which transudes across the epithelium [173-175]. VLPs against rotavirus have also been developed and have been shown to be both stable and protective against rotavirus challenge in animal models following injection [109]. Virosomes differ from VLPs as they are composed of both viral proteins and lipids, either viral or otherwise, and resemble liposomes [176]. Immunopotentiating reconstituted influenza virosomes (IRIVs) include influenza membrane proteins hemagglutinin and neuraminidase in the construct [177] and in addition to their application for influenza vaccines $[178,179]$ have been shown to be efficacious delivery vehicles for vaccines against hepatitis A [180] and HIV [181].

Although the landscape for the mucosal application of VLP and virosome-based vaccines is currently sparse, both technologies represent potential platforms to support the development of novel, nonliving oral vaccines against enteric viruses [182]. The advantages of VLPs and virosomes for oral delivery are their small size and the variable composition of their surface chemistry, which allows for the selection of appropriate electrochemical properties to ensure desirable interactions with membranes and mucus. VLPs and virosomes can also be engineered to incorporate proteins with a variety of beneficial functions including targeting and immunostimulatory activity by inserting the corresponding genes into the recombinant vector's genome. However, VLPs and virosomes both suffer from challenges in formulation, scaling up and both require extensive purification and quality control which adds to manufacturing costs compared to synthetic polymer-based systems. In addition, VLPs require the addition of adjuvants in order to elicit enhanced immune responses. However, virosomes may not require the addition of adjuvants and so may be the more attractive of the two options as oral delivery vehicles [183]. Results in mice following intra-nasal application of Noravirus-based VLPS have been encouraging and will perhaps in time lend themselves to the oral route $[184,185]$ although it may be essential to incorporate these lipid based systems in enteric capsule based formulations to enhance their oral effectiveness and protect them from the lipid digesting gastrointestinal environment.

\subsection{Synthetic particle-based strategies}

Synthetic particles are one of the most versatile oral delivery systems where a vaccine payload is either attached, adsorbed or dispersed and encapsulated within a polymer matrix (Fig. 2G). Their size can be controlled, ranging from $30 \mathrm{~nm}$ up to millimeters in size. Leveraging these technologies potentially enables the circumvention of many of the barriers imposed on mucosal vaccination allowing antigens and adjuvants to be delivered to the desired mucosa. Particles can be designed to deliver low molecular weight drugs or biological molecules upon degradation, swelling and diffusion from the polymer or change in electrostatic interactions. These delivery systems have attractive versatility due in part to the large number of potential components and formulation methods. Such factors facilitate the production of particles of defined sizes and various architectures with distinct chemical properties in order to target specific cell types or specific mucosal sites and to suit specific payloads based on desired surface charge and release kinetics. Furthermore, polymer selection can influence intrinsic adjuvant effects, biocompatibility and biodegradability. The most widely studied particles so far are those produced from poly( $\alpha$-hydroxyl acids), poly(amino acids) and polysaccharides with the most common polymers being poly(lacticco-glycolic acid) (PLGA), poly(lactic acid) (PLA), $\beta$-glucans, alginate and chitosan [186-188]. While biodegradable particles have been extensively investigated for vaccine delivery, the potential of nonbiodegradable alternatives such as carbon, silica and gold has also been suggested. The advantage of using such particles is the impressively small size at which these can be manufactured ( $2 \mathrm{~nm}-50 \mathrm{~nm})$. Small nanoparticles have been shown to greatly aid uptake of payloads across challenging physiological barriers such as the intestine and blood brain barrier. The porous nature of carbon and silica particles also provides cavities in which to load antigens and adjuvants.

Many of these particulates have already seen clinical application for drug delivery and their role in improving the efficacy of mucosal vaccination is the topic of much investigation [186]. Some of the suggested merits which make them applicable for mucosal vaccine delivery include their ability to protect the payload from degradation, penetrate the mucus barriers and to control and target the release of both antigens and adjuvants. In principle these properties can be optimised by altering particle size, surface chemistry and 3D architecture. The size of a particle plays a critical role in determining the dose of both antigen and adjuvant 
that can be loaded. When vaccinating at mucosal surfaces, it has been demonstrated that particulate antigens are often more immunogenic than antigens in solution [19]. It is thought that particulate antigens are more likely to be trafficked across the mucosa and be taken up by APCs [189]. Uptake of particles primarily occurs via M-cells (Fig. 1). Although, few studies have conclusively addressed the role of size in dictating mucosal immunity following oral delivery, there is a consensus that particles with a diameter smaller than $1 \mu \mathrm{m}$ are more readily taken up by $M$ cells [190]. In addition to the role of size in regulating the potential for trans-epithelial uptake, the ability of particles to migrate through the pores in the mucus is dependent on both size and surface electrochemical properties $[33,191]$. While $M$ cells remain a key target for particulate oral vaccines, it was recently shown that particles of 1-5 $\mu \mathrm{m}$ in size were taken up across the jejunum and ileum via non phagocytic processes, suggesting that particle uptake is not solely via M cells [192]. In the latter study, particle uptake was greater for $0.5 \mu \mathrm{m}$ and $1 \mu \mathrm{m}$ particles than for those of $2 \mu \mathrm{m}$ or $5 \mu \mathrm{m}$ in size.

Nanoparticles formulated using the copolymer PLGA are most widely used as a result of its approval [193] for applications including biodegradable sutures and controlled release properties [194]. PLGA nanoparticles have been shown to penetrate and distribute through mucosal tissue after local administration, most likely via cellular trafficking [195]. Although challenging, the surface chemistry of PLG particles can be altered to increase diffusion through mucus and uptake by $\mathrm{M}$ cells $[193,196,197]$. The architecture of PLGA nanoparticles also allows for the encapsulation of antigens and adjuvants, thus providing a protective function [196]. However, the formulation process, generation of a low $\mathrm{pH}$ during polymer hydrolyisis and exposure of surface antigens to gastrointestinal proteolysis are major challenges for PLG based oral vaccine approaches.

Nevertheless, association with PLG particles was shown to result in enhanced systemic and mucosal immune responses following vaccination by the oral $[198,199]$ and nasal $[200-202]$ route in the case of antigens from B. pertussis, V. cholerae, S. aureus, SIV as well as the toxin ricin [198-202]. The mechanisms underlying the adjuvanticity of PLG particles are currently unclear but are the subject of ongoing research. PLG nano- and microparticles enhanced IL- $1 \beta$ production by dendritic cells via a NLRP-3 inflammasome dependent process [203]. The crucial role of the IL- 1 family of cytokines in both innate and adaptive immunity is well documented $[204,205]$ although the role of the inflammasome in the induction of adaptive immunity following mucosal vaccination with particulate adjuvants is currently unclear.

Despite the promising results with PLG nano and microparticles in rodent models, progress towards clinical application has been disappointing. Oral immunization with a PLG encapsulated SIV antigen enhanced protective immunity against a subsequent intravaginal challenge with SIV [198], however, this effect was dependent on a systemic prime vaccination [198]. A phase 1 trial with orally delivered PLG-encapsulated CS6, a prominent ETEC antigen, delivered poor results in human volunteers. While well tolerated, the total number of subjects responding to the vaccine was less than 50\% [206]. While these results should not condemn the use of a particle-based approach to oral vaccines it is likely that these original formulations will need to be improved upon for example by targeting and that particles may need to be included as one component of an advanced delivery strategy.

Both synthetic and naturally occurring polymeric particulate delivery systems can be engineered to have a specific surface chemistry and composition in order to overcome mucosal barriers, interact with specific cell types and exert desired immunomodulatory functions. Altering the electrochemical properties of the particle surface can not only determine its interactions with mucus, but hydrophobic particles have been shown to engage DAMP receptors leading to activation of innate cells via this intrinsic adjuvant property [207]. Complement mediated immune activation by particles can also be achieved by adding hydroxyl groups to the surface to enhance interaction with the complement activating protein C3b [208]. Pathogen-associated molecular patterns (PAMPs) can also be attached to the surface of particles to enhance innate activation via pathogen recognition receptors including TLRs [193].

Glucan particles (GPs) are derived from Saccharomyces cerevisiae, and can enhance intestinal SIgA responses and Th1/Th17 mediated cellular responses to associated antigens following oral vaccination [209]. GPs can be efficiently loaded with antigen (>90\%), target M cells for uptake and also exhibit an intrinsic immunomodulatory capacity $[210,211]$. $\beta$-glucans are fungal PAMPs, signalling through receptors such as dectin- 1 and complement receptor 3 expressed on DCs, monocytes and neutrophils [209,212]. Furthermore GPs have been generally recognized as safe by the Food and Drug Administration [213]. However, GP manufacture is currently limited to liquid formulations, which require cold-chain storage and thus not optimal for use in poorer settings. In addition there may be a requirement to use muco-lytic agents such as $\mathrm{N}$-acetylcysteine when evaluating the oral efficacy of GPs suggesting that are susceptible to becoming trapped in the mucus layers [214].

While particle-based delivery systems offer many advantages for both antigen uptake and enhancement of mucosal immune responses, antigens can be exposed to degradative steps during manufacture. Particles are often formulated using emulsification techniques requiring organic solvents [215] although there are other approaches include gelation of polymers suspended in emulsion droplets when the suspension is exposed to a change in temperature, $\mathrm{pH}$ or addition of crosslinking agents [216]. By tailoring polymers and formulation conditions, it is possible to exert control over intrinsic triggers for antigen release ( $\mathrm{pH}$, the presence of certain enzymes etc.) as well as the rate of degradation [217]. Depending on their specific nature, labile antigens can be damaged by high shear rates, use of organic solvents and elevated temperatures. In order to overcome these challenges, some groups have adsorbed or conjugated antigens to the surface of particles, thereby sparing antigens the harsher manufacturing steps that may result in their destruction (Fig. 2G). However, in the context of oral vaccination, as antigens are now on the surface of particles, this exposes them to the degradative environments of the GIT. This poses additional delivery challenges, which need to be overcome to ensure protection of the payload.

\subsection{Tablets and capsules}

In contrast to micro and nanoparticles, capsules are significantly larger in size and contain one or multiple reservoirs of a vaccine formulation usually suspended or dissolved in an oil- based or aqueous solution, encapsulated in a solid or semi-solid shell. While no subunit or WCK oral vaccine is currently delivered by capsule or tablet, the live attenuated Salmonella vaccine Vivotif® and many drugs and supplements are routinely delivered using this strategy. Capsular approaches exploit an appropriate physical size (average capsules/tablets range from $5 \mathrm{~mm}$ to $20 \mathrm{~mm}$ in size) and these systems can be highly versatile. In principle, capsules allow for the incorporation of many, if not all of the previously introduced delivery technologies in a primary delivery vehicle that can be loaded with an accurate dose during manufacture. In fact, this may be an essential requirement in most cases to protect and increase the effectiveness of these systems. It is suggested that some capsules and tablets can be designed to enhance the stability of vaccines to environmental conditions such as high humidity and temperature, which may reduce the need for specific storage conditions and can greatly reduce the cost of implementing such a strategy in the field. Recently a tablet-based oral influenza vaccine was shown to elicit strong anti-viral antibody and cellular responses against avian flu antigens in humans [218]. This approach utilized a non-replicating adenovirus vector expressing avian flu antigens together with a TLR3 agonist [218]. This approach may be adaptable to an oral vaccine against adenoviral diarrheal infections, which have significant incidence in children, especially in developing countries [219]. Using capsules, it may be possible to adapt delivery technologies designed for other mucosal tissues 
Table 2

Common oral delivery systems

\begin{tabular}{|c|c|c|c|}
\hline $\begin{array}{l}\text { Delivery } \\
\text { System }\end{array}$ & Application & Advantages & Disadvantages \\
\hline Solution & $\begin{array}{l}\text { Live attenuated, WCK, proteins, peptides, } \\
\text { conjugates other delivery systems }\end{array}$ & Inexpensive buffer, flexible & $\begin{array}{l}\text { Often requires the use of bicarbonate salts to } \\
\text { neutralise stomach acid, dilution of formulation, } \\
\text { lack of clean water in poor nations }\end{array}$ \\
\hline Emulsions & WCK, proteins, peptides, conjugates & $\begin{array}{l}\text { Potential for different formulations to } \\
\text { facilitate specific immunomodulation e.g. } \\
\text { Th1 (Water-in-oil) and Th2 (Oil-in-water) }\end{array}$ & $\begin{array}{l}\text { Does not protect vaccine from GIT environment, } \\
\text { efficacy by the oral route uncertain }\end{array}$ \\
\hline Virus-like Particles & $\begin{array}{l}\text { Plasmid DNA, proteins, peptides, } \\
\text { conjugates }\end{array}$ & $\begin{array}{l}\text { Non-replicating, high uptake, self-assembling, } \\
\text { can conjugate additional molecules to provide } \\
\text { targeted tissue/cell specificity }\end{array}$ & $\begin{array}{l}\text { Recombinant technology is expensive and difficult } \\
\text { to scale up, requires purification and often } \\
\text { incorporation of additional adjuvants }\end{array}$ \\
\hline Liposomes & Proteins, DNA, peptides & $\begin{array}{l}\text { Surface can easily be modified, suits a wide } \\
\text { variety of antigen types, controlled release }\end{array}$ & $\begin{array}{l}\text { Poor antigen loading efficiency, low stability, } \\
\text { non-specific interactions, toxicity of cationic } \\
\text { liposomes, degradation by bile sales and lipases }\end{array}$ \\
\hline ISCOMs & Proteins, peptides & $\begin{array}{l}\text { Intrinsic adjuvant capabilities, ease of antigen loading, } \\
\text { can modify surface, efficient induction of CTLs }\end{array}$ & Loading hydrophobic antigens is difficult \\
\hline Synthetic Particles & Proteins, peptides, Conjugates & $\begin{array}{l}\text { High adaptable, can protect contents from both } \\
\text { environmental and physiological effects, controlled } \\
\text { release, modifiable surface chemistry }\end{array}$ & $\begin{array}{l}\text { Low loading efficiency, manufacturing process may } \\
\text { degrade antigens, surface antigen exposed } \\
\text { to proteolysis, can become trapped in mucus }\end{array}$ \\
\hline Pills and Capsules & $\begin{array}{l}\text { Live attenuated, WCK, proteins, peptides, } \\
\text { conjugates other delivery systems }\end{array}$ & $\begin{array}{l}\text { High adaptable, can protect contents from both } \\
\text { environmental and physiological challenges, } \\
\text { controlled release, easy to administer }\end{array}$ & $\begin{array}{l}\text { Formulation process may damage components, } \\
\text { loading complications }\end{array}$ \\
\hline
\end{tabular}

towards improved oral vaccines. For example, enteric coatings can be applied to tablets and capsules, imparting protection from gastric $\mathrm{pH}$ and controlled release properties, which can facilitate delivery to discrete locations. Furthermore, the composition of the vehicle can be tailored in such a way that it aids in the release of poorly-soluble components, facilitates sustained release over time or allows sequential release of various components allowing for a considerable degree of flexibility.

An interesting recent development has been the expression of recombinant antigens in plants with a view to producing edible vaccines, especially those utilizing rice as a vector due to the natural resistance of rice grains to degradation in the stomach [220]. MucoRice is a prophylactic anti-toxic cholera vaccine that has shown promise in both murine and non-human primate preclinical studies [98,221,222]. The CTB content of each grain of MucoRice was found to be approximately $30 \mu \mathrm{g}$ [220]. The consistency of these results is important when measuring the dose of antigen delivered to each vaccinee, however considering the total percentage of protein in each grain represented by СТВ is $2.1 \%$, the total weight of CTB per grain can be calculated at $0.15 \%$ allowing for dosing based on the weight of grains [220]. If successful, such a system could provide a rapidly scalable and economically viable solution to mass oral vaccination [221]. CTB found in MucoRice is localized inside protein bodies within the rice grains, therefore providing protection from the harsh environment of the GIT and thus MucoRice acts in a similar fashion to a capsule for the delivery of CTB to gut inductive sites [221]. A similar rice-based oral vaccine against rotavirus has also shown promise in murine studies [223]. Human trials will in time reveal if such a system can indeed provide a sustainable solution to eradicating enteric diarrhea.

\section{Technical adaptations to oral delivery vehicles}

While next generation antigens, powerful adjuvants and a suitable delivery system have been demonstrated to greatly enhance the efficacy of many mucosal and parenteral vaccines, there remain many oral route-specific challenges that must be overcome. Various technological adaptations can be made to augment oral delivery systems in order to adapt them for purpose and enhance their existing capabilities.

\subsection{Protection against degradation}

An effective oral vaccine formulation can only elicit a protective immune response when delivered intact and to the appropriate anatomical location in the GIT. The vaccine must also be formulated in such a way as to maximize its immunogenicity. Selecting the appropriate formulation method and delivery vehicle can promote mucosal antigen uptake and immune activation. While oral vaccines delivered in solution can be given with a buffered solution to neutralise gastric acidity, significant dilution of vaccine contents and enzymatic degradation can still occur so efficacy may be improved using a suitable delivery system (Table 2).

The tri-polymer Eudragit ${ }^{\circledR}$ FS30D is known to remain intact at a pH below 7 allowing transport of a coated particle through the stomach and duodenum. Recently, particles coated in this polymer were shown to selectively release their payload in the terminal ileum [224]. Similarly, Eudragit ${ }^{\circledR}$ FS30D was shown to remain stable at low pH and a subsequent increase in $\mathrm{pH}$ led to a sustained release of WCK V. cholerae antigen from alginate micro-particles in in vitro models [225]. Coating a particle in this way can increase its size, thereby potentially compromising its uptake at the mucosal interface. However, premature uptake of the particle may be prevented until the coating completely degrades thus facilitating tissue specific release. Enteric coatings can also be applied to lipid-based delivery systems such as liposomes. Such coatings can protect liposomes from the degradative actions of bile salts and lipases. The use of a fungal derived polymer coating allowed for enhanced mucosal responses in the GIT following oral vaccination with liposomes [156]. Furthermore, altering the composition of lipids in these membranes can add stability in acidic environments. The use of dipalmitoyl phosphatidyserine, dipalmitoyl-phosphatidylcholine and cholesterol can enhance the resistance of liposomes to acidic $\mathrm{pH}[226,227]$.

The use of coatings on particles is an attractive means to protect exposed antigens and to achieve controlled release. PLG micro-particles stabilised using either EUDRAGIT ${ }^{\circledR}$ L100-55 or carboxymethylethylcellulose (CMCE) were rendered resistant to gastric degradation thus protecting encapsulated ovalbumin (OVA) [228]. CMCE-stabilized micro-particles were also capable of eliciting greater systemic and mucosal immune responses compared to EUDRAGIT® L100-55 following oral immunisation in mice [228]. This approach was adopted as encapsulation in PLG particles stabilised using the conventional poly (vinyl alcohol) stabiliser led to surface exposure of the antigen which was highly sensitive to gastric proteolysis. While there remain issues with the oral use of PLG particles including the well-documented burst effect and challenges relating to damage to antigens during encapsulation and as a result of polymer hydrolysis, surface adsporption or attachment of antigens and incorporation in a protective enteric capsule may provide a productive avenue for further studies. This could be further enhanced by 
the use of specific targeting ligands. EUDRAGIT® L 30 D-55 coating of an oral cholera micro-particle based vaccine composed of WCK $V$. cholerae incorporated into micro-particles resulted in enhanced immunogenicity in a rat model [225]. The polymer did not compromise antigen stability and led to minimal antigen release under low pH conditions [225] but release increased rapidly at an elevated $\mathrm{pH}$ [225]. In addition to protecting antigens from low $\mathrm{pH}$, coatings can be used to facilitate controlled antigen release in the intestine which may contribute to enhanced immunogenicity. A number of studies have suggested that the combination of initial high doses followed by a sustained release of antigen could help overcome the predisposition towards tolerance [86, $229,230]$. Sustained antigen exposure may contribute to the efficacy of the oral polio vaccine as the attenuated virus establishes a limited local infection, providing both innate stimuli via PAMPs and a reservoir of antigen to establish a memory response [26].

\subsection{Targeted delivery to specific tissues and cells}

To induce effective mucosal immune responses in the gut it is desirable to direct a vaccine towards the main sites of antigen entry and immune activation (Fig. 1). The pivotal role played by $\mathrm{M}$ cells in the uptake of intestinal antigens has made them a key target for oral vaccine delivery. The unique glycosylation pattern displayed by these cells suggested the potential for specific targeting with lectins [231]. Targeting of particulates to murine intestinal M cells with the $\alpha$-L-fucose specific lectin, Ulex europaeus agglutinin-1 (UEA- 1) resulted in enhanced uptake [232,233]. Furthermore, a low molecular weight UEA-1 peptidomimetic has also been shown to enhance particle uptake after oral delivery [234]. Nasal delivery of a UEA-1 mimetic targeted micro-particulate antigen resulted in enhanced immune responses following intranasal delivery [235]. Furthermore, both nasal and oral delivery of lectin-targeted nanoparticles (300-390 nm) promoted antigen specific cellular immunity in the absence of mucosal or systemic antibody responses [201]. Liposomes can also be targeted to $\mathrm{M}$ cells following oral administration utilizing UEA-1 [155]. Recent findings have also demonstrated that fucosylation patterns on IECs can be influenced by TLR agonists [236], opening up new possibilities for vaccine targeting. However, since $M$ cells in the upper respiratory tract differ significantly from those in Peyer's patches [83-85], one cannot infer that all targeting strategies that are effective by the nasal route will be effective orally.

An alternative targeting approach involves the use of M-cell specific antibodies conjugated to particulates in order to enhance uptake in the GIT [237]. Antibody coated delivery systems such as liposomes and micro-particles may target mechanisms that sample antibody coated bacteria from the intestinal lumen and delivery these to APCs [238, 239]. Additionally it may be possible to exploit the same mechanisms used by enteric pathogens for invasion to enhance the uptake of oral vaccines. Particles coated in Yersinia-derived invasins displayed enhanced uptake via $\beta 1$ integrins expressed on the apical side of M cells [240]. Mannose-binding fimbriae expressed on Salmonella and invasive E. coli could also be used to enhance antigen uptake by M cells in a similar manner to GP2 binding antibodies [53] and the fimbriae have the additional benefit of enhancing mucosal innate immunity via TLR5 and NLRC4. Enhanced mucosal immune responses were reported when antigens were coupled the $\mathrm{M}$ cell targeting $\sigma 1$ reovirus protein [241]. However, while targeting of antigens attached to micro and nanoparticle surfaces is a promising approach, the exposure of the antigens to gastrointestinal secretions is a major obstacle. To increase efficacy and enhance the potential for translation, coatings or capsule strategies will be required to facilitate delivery of the targeted particles to immune inductive sites intact.

In addition to the clear benefits of targeting intestinal $\mathrm{M}$ cells, because of the key role they play in eliciting mucosal immune responses and their position at the frontline of the mucosa, many strategies to target mucosal DCs have been developed. Specific targeting of vaccines to DC specific receptors was pioneered by the late Ralph Steinman [242,
243]. Examples of such DC-specific receptors include CD205/DEC205 and DC-specific intercellular adhesion molecule 3-grabbing nonintegrin (DC-SIGN) [244]. DC-SIGN has also been shown to recognize SIgA which may present a novel targeting strategy [245]. Targeting of DCs can also be coupled to the delivery of TLR ligands as adjuvants which potently enhanced the ability of this approach to enhance Th1-mediated responses following subcutaneous vaccination [246].

Expression patterns of different DC-specific receptors varies between different mucosal DC subsets, and between mature and immature DCs [247]. One must also consider the intracellular routing following uptake by specific receptors as these may influence the consequent antigen presentation pathways that the antigens enter. This avenue has not yet been explored in depth in the context of oral vaccination but in parallel with $\mathrm{M}$ cell targeting, optimal targeting of particulates to gut DC and other mononuclear cell populations should be considered.

Other factors that influence the optimal choice of delivery system include the type and numbers of inductive sites, particularly PPs which are more numerous in the ileum, and competition from dietary and commensal antigen, the former of which are most abundant in the duodenum and the latter in the terminal ileum and caecum [34]. The relative abundance of cell populations such as iNKT and MAIT cells, activators of which may present novel adjuvant opportunities, also vary along the GIT but seem to be predominantly located in the jejunum $[34,135]$. Additionally specific DC subsets vary in abundance in different regions of the GIT, making the targeting of individual subsets reliant on the correct anatomical localisation of the delivery system [34].

\subsection{Muco-adhesion and delivery}

Considering the benefits of antigen persistence at immune inductive sites for enhancing uptake in the intestine, muco-adhesion and mucopenetration strategies may offer benefits for enhancing immunogenicity. A vaccine administered to a site of rapid mucus clearance may benefit from enhanced muco-penetration, whereas at a site with lower rates of mucus clearance, muco-adhesion may facilitate longer residence. To this end it is thought that more hydrophilic carriers with net-neutral surfaces exhibit enhanced muco-penetration, while muco-adhesion can be achieved by highly hydrophobic or positively charged surfaces which interact with the largely negatively charged mucus, thus prolonging the presence of the carrier in the mucus layer [33]. In addition to the potential for vaccine muco-adhesion to prolong the exposure of the vaccine to GALT tissues, this approach may also limit the dilution of vaccine material in gastrointestinal secretions. Work on naturally occurring biomaterials such chitosan (a compound formed by the deacetylation of chitin) has revealed that its strong muco-adhesive properties stem from the presence of numerous hydrogen-bond forming groups [248]. Other research has shown that altering the ionic strength of the buffer can increase particle diffusion through the mucus and uptake by $M$ cells [197]. A novel nanogel technology developed by Kiyono and colleagues enables the persistence of vaccine material in the nasal passage after administration, ensuring adequate antigen exposure $[249,250]$. This system has recently been evaluated in a non-human primate model where intra-nasal administration of pneumococcal surface protein A in nanogel led to robust mucosal and systemic immune responses and provided protection from Streptococcus pneumoniae challenge [251]. While, there are no published data on the efficacy of the nanogel by the oral route, its application as an oral delivery strategy has been patented [252].

Plant-based muco-adhesives such as those derived from aloe also have potential to enhance gut residence through promotion of an antigen depot effect [253]. Muco-adhesives such as carboxy vinyl polymers have also been shown to prolong antigen persistence in the intestine, increasing the potential for antigen uptake [254]. Formulating particulates directly from or coating them with muco-adhesive molecules [255] combines the benefits of both particulate antigen presentation and enhanced mucosal residence times. In addition to its muco-adhesive 
properties, chitosan may enhance uptake by opening tight junctions [256] as well as displaying intrinsic adjuvant effects [257]. Depending on the target site in the GIT, the choice of muco-penetrating agent or muco-adhesive agent may play a decisive role in navigating the system through thicker mucus layers or allowing persistence of the formulation at areas of more rapid clearance.

\section{Conclusions and future perspectives}

The efficacy of OPV and other oral vaccines against Cholera, Traveller's Diarrhoea, Noravirus, Rotavirus and S. typhi (Table 1) [19] demonstrates the great potential of oral vaccination. In depth studies into the effectiveness of oral cholera and polio vaccines has served as not only a strong proof-of-concept but also a testament to the benefit of wide scale oral vaccination campaigns $[15,258,259]$. However, the development of new oral WCK and subunit vaccines is hampered by the many physical, chemical and immunological challenges posed by delivery to the gastrointestinal tract. Despite this, many prototype vaccines against enteric infections including ETEC, other pathogenic E. coli strains and $H$. pylori and improvements to existing oral vaccines have emerged, demonstrating the significant degree of interest in this field [19]. The potential for triggering protective intestinal humoral and cellular immunity to block infection remains very attractive and justifies interest in developing advanced delivery solutions (Table 2 ). While many candidate and prototype oral vaccine delivery systems for nonliving vaccines have been investigated to date, none have been licensed for clinical application in humans, with most remaining largely in the early development or pre-clinical phase. Given the many challenges, approaches that combine solutions to multiple hurdles in a single formulation may be required (Fig. 3). Integrated systems that can address the challenges of low gastric $\mathrm{pH}$, dilution effects, targeting of immune inductive sites and the need to include potent orally active adjuvants should be considered. Following safe passage through the gastric environment (Fig. 3A) and controlled and sustained release, the payload would be delivered to the target site by either a lipid-based or nano/micro-particulate subdelivery system (Fig. 3B), thereby ensuring adequate uptake of vaccine components, activation of innate immune cells and the induction of mucosal and systemic adaptive immune responses (Fig. 3C). In this context,

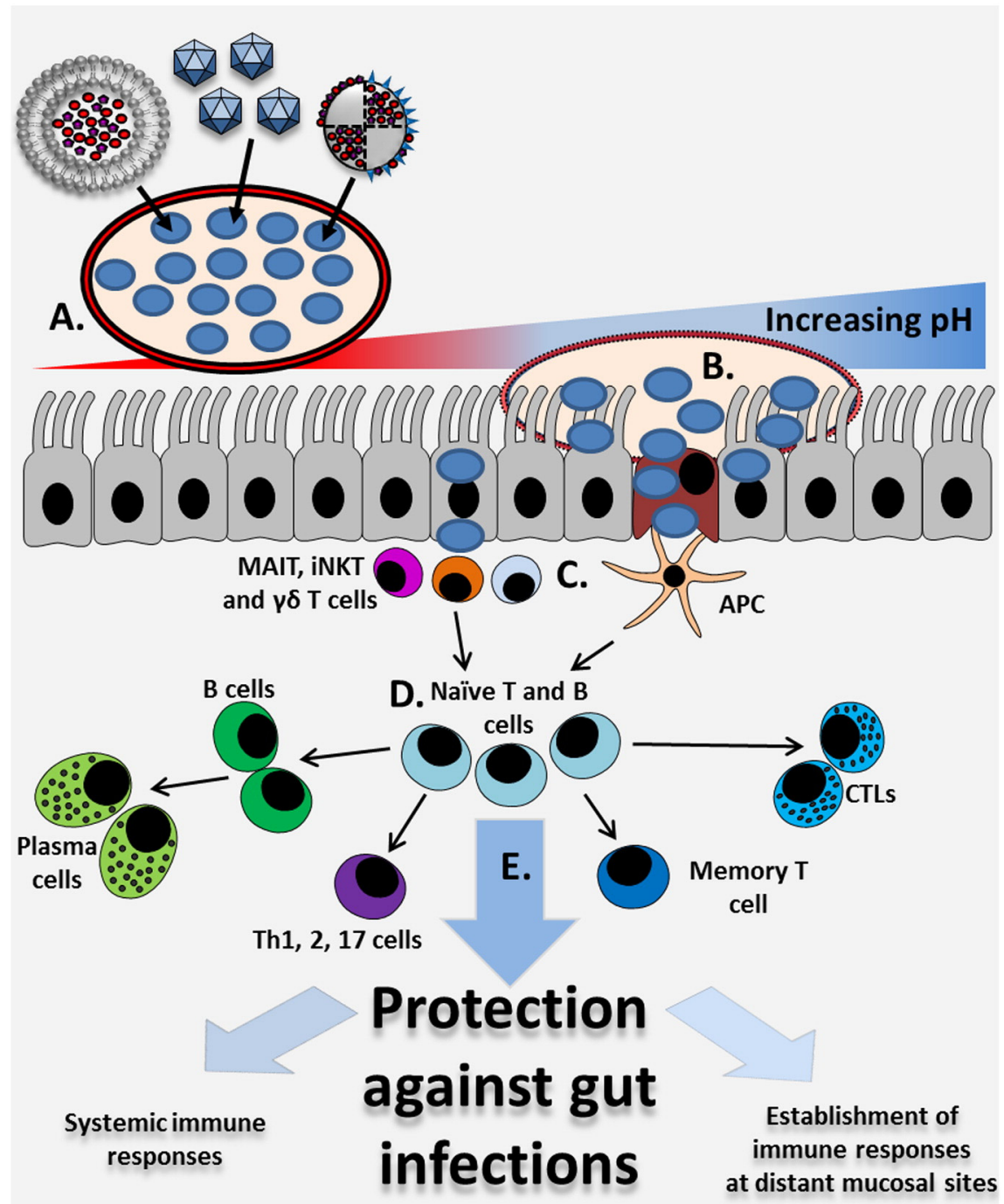

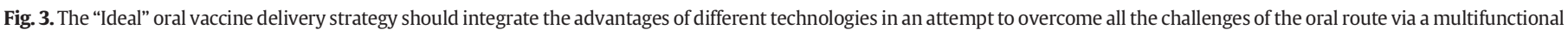

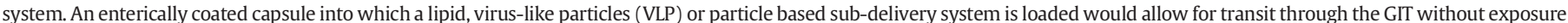

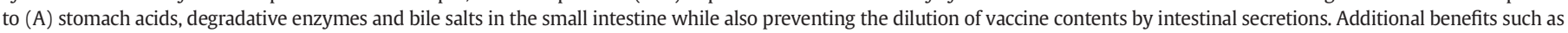

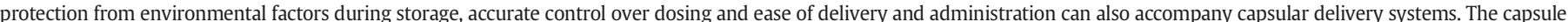

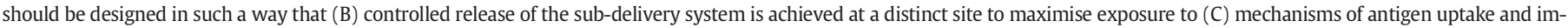

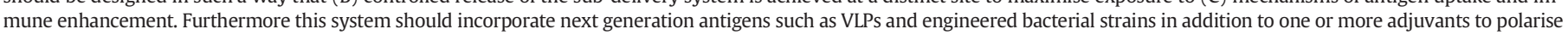
and enhance the desired (E) effector and memory response. 
next-generation antigens such as bacterial vectors over-expressing antigens or VLPs that improve immunogenicity but also reduce cost through simplified manufacture and dose sparing could be considered. A key and pressing challenge is the identification of potent orally active and safe adjuvants for vaccination in humans. Understanding of intestinal innate immunity has greatly advanced over recent years offering valuable new insights for the design of optimal mucosal adjuvants. Although human trials of many oral delivery systems have delivered disappointing results, these have principally focused on the efficacy of specific adjuvants or delivery systems in isolation. We propose that the potential of many oral vaccine delivery systems could be enhanced if used as a subcomponent of a larger delivery strategy. Such a system would likely compose a larger pill or capsule based "Super" delivery system containing a particle or liposomebased sub-delivery system as part of a controlled release mechanism.

\section{Acknowledgements}

The work on oral vaccines conducted in the Lavelle laboratory is supported by Science Foundation Ireland (SFI) under Grant number 12/IA/1421 and the SFI Research Centre, Advanced Materials and BioEngineering Research (AMBER) under Grant number SFI/12/RC/ 2278, the European Union FP7 programme HELICOVAXOR (2013), FP7-SME-2012-1 (Research For SMEs) and the Irish Research Council.

\section{References}

[1] A.C. Cheng, J.R. McDonald, N.M. Thielman, Infectious diarrhea in developed and developing countries, J. Clin. Gastroenterol. 39 (2005) 757-773.

[2] L. Liu, H.L. Johnson, S. Cousens, J. Perin, S. Scott, J.E. Lawn, I. Rudan, H. Campbell, R. Cibulskis, M. Li, C. Mathers, R.E. Black, W.H.O. Child Health Epidemiology Reference Group of, Unicef, Global, regional, and national causes of child mortality: an updated systematic analysis for 2010 with time trends since 2000, Lancet 379 (2012) 2151-2161

[3] W.A. Petri Jr., M. Miller, H.J. Binder, M.M. Levine, R. Dillingham, R.L. Guerrant, Enteric infections, diarrhea, and their impact on function and development, J. Clin. Invest. 118 (2008) 1277-1290.

[4] K.L. Kotloff, J.P. Nataro, W.C. Blackwelder, D. Nasrin, T.H. Farag, S. Panchalingam, Y. Wu, S.O. Sow, D. Sur, R.F. Breiman, A.S. Faruque, A.K. Zaidi, D. Saha, P.L. Alonso, B. Tamboura, D. Sanogo, U. Onwuchekwa, B. Manna, T. Ramamurthy, S. Kanungo, J.B. Ochieng, R. Omore, J.O. Oundo, A. Hossain, S.K. Das, S. Ahmed, S. Qureshi, F. Quadri, R.A. Adegbola, M. Antonio, M.J. Hossain, A. Akinsola, I. Mandomando, T. Nhampossa, S. Acacio, K. Biswas, C.E. O'Reilly, E.D. Mintz, L.Y. Berkeley, K. Muhsen, H. Sommerfelt, R.M. Robins-Browne, M.M. Levine, Burden and aetiology of diarrhoeal disease in infants and young children in developing countries (the Global Enteric Multicenter Study, GEMS): a prospective, case-control study, Lancet 382 (2013) 209-222.

[5] A.M. Svennerholm, From cholera to enterotoxigenic Escherichia coli (ETEC) vaccine development, Indian J. Med. Res. 133 (2011) 188-196.

[6] J. Tobias, A.M. Svennerholm, Strategies to overexpress enterotoxigenic Escherichia coli (ETEC) colonization factors for the construction of oral whole-cell inactivated ETEC vaccine candidates, Appl. Microbiol. Biotechnol. 93 (2012) 2291-2300.

[7] A. Huq, R.B. Sack, A. Nizam, I.M. Longini, G.B. Nair, A. Ali, J.G. Morris Jr., M.N. Khan, A.K. Siddique, M. Yunus, M.J. Albert, D.A. Sack, R.R. Colwell, Critical factors influencing the occurrence of Vibrio cholerae in the environment of Bangladesh, Appl. Environ. Microbiol. 71 (2005) 4645-4654.

[8] Health Cluster Bulletin \#15, Pan American Health Organization, http://new.paho. org/hai/index.php?lang5en.

[9] N.J. Carter, M.P. Curran, Live attenuated influenza vaccine (FluMist(R); Fluenz): a review of its use in the prevention of seasonal influenza in children and adults, Drugs 71 (2011) 1591-1622.

[10] D.D. Anh, A.L. Lopez, V.D. Thiem, S.L. Grahek, T.N. Duong, J.K. Park, H.J. Kwon, M. Favorov, N.T. Hien, J.D. Clemens, Use of oral cholera vaccines in an outbreak in Vietnam: a case control study, PLoS Negl. Trop. Dis. 5 (2011) e1006.

[11] K.A. Date, A. Vicari, T.B. Hyde, E. Mintz, M.C. Danovaro-Holliday, A. Henry, J.W. Tappero, T.H. Roels, J. Abrams, B.T. Burkholder, C. Ruiz-Matus, J. Andrus, V. Dietz, Considerations for oral cholera vaccine use during outbreak after earthquake in Haiti, 2010-2011, Emerg. Infect. Dis. 17 (2011) 2105-2112.

[12] N.J. Mantis, L.A. Morici, C.J. Roy, Mucosal vaccines for biodefense, Curr. Top. Microbiol. Immunol. 354 (2012) 181-195.

[13] S. Riedel, Edward Jenner and the history of smallpox and vaccination, Proc. (Baylor Univ. Med. Cent.) 18 (2005) 21-25.

[14] K.P. Murphy, P. Travers, M. Walport, C. Janeway, Janeway's immunobiology, 7th ed. Garland Science, New York, 2008.

[15] J. Modlin, J. Wenger, Achieving and maintaining polio eradication-new strategies, N. Engl. J. Med. 371 (2014) 1476-1479.

[16] P.M. Strebel, R.W. Sutter, S.L. Cochi, R.J. Biellik, E.W. Brink, O.M. Kew, M.A Pallansch, W.A. Orenstein, A.R. Hinman, Epidemiology of poliomyelitis in the
United States one decade after the last reported case of indigenous wild virusassociated disease, Clin. Infect. Dis. 14 (1992) 568-579.

[17] M.M. Levine, Immunogenicity and efficacy of oral vaccines in developing countries: essons from a live cholera vaccine, BMC Biol. 8 (2010) 129

[18] R.I. Walker, Considerations for development of whole cell bacterial vaccines to prevent diarrheal diseases in children in developing countries, Vaccine 23 (2005) 3369-3385.

[19] N. Lycke, Recent progress in mucosal vaccine development: potential and limitations, Nat. Rev. Immunol. 12 (2012) 592-605.

[20] M.M. Levine, G. Dougan, Optimism over vaccines administered via mucosal surfaces, Lancet 351 (1998) 1375-1376.

[21] Y. Yuki, H. Kiyono, Mucosal vaccines: novel advances in technology and delivery, Expert Rev. Vaccines 8 (2009) 1083-1097.

[22] R. Alcock, M.G. Cottingham, C.S. Rollier, J. Furze, S.D. De Costa, M. Hanlon, A.J Spencer, J.D. Honeycutt, D.H. Wyllie, S.C. Gilbert, M. Bregu, A.V. Hill, Long-term thermostabilization of live poxviral and adenoviral vaccine vectors at supraphysiological temperatures in carbohydrate glass, Sci. Transl. Med. 2 (2010) $19 r a 12$.

[23] M. Pastor, A. Esquisabel, A. Talavera, G. Ano, S. Fernandez, B. Cedre, J.F. Infante, A Callico, J.L. Pedraz, An approach to a cold chain free oral cholera vaccine: in vitro and in vivo characterization of Vibrio cholerae gastro-resistant microparticles, Int J. Pharm. 448 (2013) 247-258.

[24] M.R. Neutra, E. Pringault, J.P. Kraehenbuhl, Antigen sampling across epithelia barriers and induction of mucosal immune responses, Annu. Rev. Immunol. 14 (1996) 275-300.

[25] J. Holmgren, C. Czerkinsky, Mucosal immunity and vaccines, Nat. Med. 11 (2005) S45-S53.

[26] M.F. Pasetti, J.K. Simon, M.B. Sztein, M.M. Levine, Immunology of gut mucosal vaccines, Immunol. Rev. 239 (2011) 125-148.

[27] J. John, S. Giri, A.S. Karthikeyan, M. Iturriza-Gomara, J. Muliyil, A. Abraham, N.C. Grassly, G. Kang, Effect of a single inactivated poliovirus vaccine dose on intestinal immunity against poliovirus in children previously given oral vaccine: an openlabel, randomised controlled trial, Lancet 384 (2014) 1505-1512.

[28] J. Holmgren, A.M. Svennerholm, Vaccines against mucosal infections, Curr. Opin. Immunol. 24 (2012) 343-353.

[29] M. Schenk, C. Mueller, The mucosal immune system at the gastrointestinal barrier Best Pract. Res. Clin. Gastroenterol. 22 (2008) 391-409.

[30] S.K. Lai, D.E. O'Hanlon, S. Harrold, S.T. Man, Y.Y. Wang, R. Cone, J. Hanes, Rapid transport of large polymeric nanoparticles in fresh undiluted human mucus, Proc. Natl. Acad. Sci. U. S. A. 104 (2007) 1482-1487.

[31] R.A. Cone, Barrier properties of mucus, Adv. Drug Deliv. Rev. 61 (2009) 75-85.

[32] A.P. Corfield, D. Carroll, N. Myerscough, C.S. Probert, Mucins in the gastrointestina tract in health and disease, Front. Biosci. 6 (2001) D1321-D1357.

[33] S.K. Lai, Y.Y. Wang, J. Hanes, Mucus-penetrating nanoparticles for drug and gene delivery to mucosal tissues, Adv. Drug Deliv. Rev. 61 (2009) 158-171.

[34] A.M. Mowat, W.W. Agace, Regional specialization within the intestinal immune system, Nat. Rev. Immunol. 14 (2014) 667-685.

[35] S.K. Lai, K. Hida, S. Shukair, Y.Y. Wang, A. Figueiredo, R. Cone, T.J. Hope, J. Hanes Human immunodeficiency virus type 1 is trapped by acidic but not by neutralized human cervicovaginal mucus, J. Virol. 83 (2009) 11196-11200.

[36] M.R. Neutra, P.A. Kozlowski, Mucosal vaccines: the promise and the challenge, Nat Rev. Immunol. 6 (2006) 148-158.

[37] A. Ermund, A. Schutte, M.E. Johansson, J.K. Gustafsson, G.C. Hansson, Studies of mucus in mouse stomach, small intestine, and colon. I. Gastrointestinal mucus layers have different properties depending on location as well as over the Peyer's patches, Am. J. Physiol. Gastrointest. Liver Physiol. 305 (2013) G341-G347.

[38] T.T. Kararli, Comparison of the gastrointestinal anatomy, physiology, and biochemistry of humans and commonly used laboratory animals, Biopharm. Drug Dispos. 16 (1995) 351-380.

[39] D.A. Sack, F. Qadri, A.M. Svennerholm, Determinants of responses to oral vaccines in developing countries, Ann. Nestle Eng. 66 (2008) 71-79.

[40] D.R. Kaufman, J. De Calisto, N.L. Simmons, A.N. Cruz, E.J. Villablanca, J.R. Mora, D.H. Barouch, Vitamin A deficiency impairs vaccine-elicited gastrointestinal immunity, J. Immunol. 187 (2011) 1877-1883.

[41] Y. Valdez, E.M. Brown, B.B. Finlay, Influence of the microbiota on vaccine effectiveness, Trends Immunol. 35 (2014) 526-537.

[42] J.H. Niess, S. Brand, X. Gu, L. Landsman, S. Jung, B.A. McCormick, J.M. Vyas, M. Boes, H.L. Ploegh, J.G. Fox, D.R. Littman, H.C. Reinecker, CX3CR1-mediated dendritic cell access to the intestinal lumen and bacterial clearance, Science 307 (2005) 254-258.

[43] M. Rescigno, M. Urbano, B. Valzasina, M. Francolini, G. Rotta, R. Bonasio, F. Granucci, J.P. Kraehenbuhl, P. Ricciardi-Castagnoli, Dendritic cells express tight junction proteins and penetrate gut epithelial monolayers to sample bacteria, Nat. Immunol. 2 (2001) 361-367.

[44] M.H. Jang, M.N. Kweon, K. Iwatani, M. Yamamoto, K. Terahara, C. Sasakawa, T. Suzuki, T. Nochi, Y. Yokota, P.D. Rennert, T. Hiroi, H. Tamagawa, H. Iijima, J. Kunisawa, Y. Yuki, H. Kiyono, Intestinal villous M cells: an antigen entry site in the mucosal epithelium, Proc. Natl. Acad. Sci. U. S. A. 101 (2004) 6110-6115.

[45] V.B. Jensen, J.T. Harty, B.D. Jones, Interactions of the invasive pathogens Salmonella typhimurium, Listeria monocytogenes, and Shigella flexneri with $\mathrm{M}$ cells and murine Peyer's patches, Infect. Immun. 66 (1998) 3758-3766.

[46] J.R. McDole, L.W. Wheeler, K.G. McDonald, B. Wang, V. Konjufca, K.A. Knoop, R.D. Newberry, M.J. Miller, Goblet cells deliver luminal antigen to CD103+ dendritic cells in the small intestine, Nature 483 (2012) 345-349.

[47] M.R. Neutra, A. Frey, J.P. Kraehenbuhl, Epithelial M cells: gateways for mucosa infection and immunization, Cell 86 (1996) 345-348. 
[48] N.A. Mabbott, D.S. Donaldson, H. Ohno, I.R. Williams, A. Mahajan, Microfold (M) cells: important immunosurveillance posts in the intestinal epithelium, Mucosal Immunol. 6 (2013) 666-677.

[49] D.D.L. Thejani, E. Rajapaksa, Microencapsulation of vaccine antigens and adjuvants for mucosal targeting, Curr. Immunol. Rev. 6 (2010) 29-37.

[50] P.J. Giannasca, K.T. Giannasca, A.M. Leichtner, M.R. Neutra, Human intestinal M cells display the sialyl Lewis A antigen, Infect. Immun. 67 (1999) 946-953.

[51] S.W. Craig, J.J. Cebra, Peyer's patches: an enriched source of precursors for IgAproducing immunocytes in the rabbit, J. Exp. Med. 134 (1971) 188-200.

[52] T. Shikina, T. Hiroi, K. Iwatani, M.H. Jang, S. Fukuyama, M. Tamura, T. Kubo, H. Ishikawa, H. Kiyono, IgA class switch occurs in the organized nasopharynx- and gut-associated lymphoid tissue, but not in the diffuse lamina propria of airways and gut, J. Immunol. 172 (2004) 6259-6264.

[53] K. Hase, K. Kawano, T. Nochi, G.S. Pontes, S. Fukuda, M. Ebisawa, K. Kadokura, T. Tobe, Y. Fujimura, S. Kawano, A. Yabashi, S. Waguri, G. Nakato, S. Kimura, T. Murakami, M. Iimura, K. Hamura, S. Fukuoka, A.W. Lowe, K. Itoh, H. Kiyono, H. Ohno, Uptake through glycoprotein 2 of FimH $(+)$ bacteria by M cells initiates mucosal immune response, Nature 462 (2009) 226-230.

[54] T. Kanaya, K. Hase, D. Takahashi, S. Fukuda, K. Hoshino, I. Sasaki, H. Hemmi, K.A Knoop, N. Kumar, M. Sato, T. Katsuno, O. Yokosuka, K. Toyooka, K. Nakai, A. Sakamoto, Y. Kitahara, T. Jinnohara, S.J. McSorley, T. Kaisho, I.R. Williams, H. Ohno, The Ets transcription factor Spi-B is essential for the differentiation of intestinal microfold cells, Nat. Immunol. 13 (2012) 729-736.

[55] H. Lelouard, M. Fallet, B. de Bovis, S. Meresse, J.P. Gorvel, Peyer's patch dendritic cells sample antigens by extending dendrites through $\mathrm{M}$ cell-specific transcellular pores, Gastroenterology 142 (2012) 592-601.e593.

[56] F. Sierro, B. Dubois, A. Coste, D. Kaiserlian, J.P. Kraehenbuhl, J.C. Sirard, Flagellin stimulation of intestinal epithelial cells triggers CCL20-mediated migration of dendritic cells, Proc. Natl. Acad. Sci. U. S. A. 98 (2001) 13722-13727.

[57] M. Ebisawa, K. Hase, D. Takahashi, H. Kitamura, K.A. Knoop, I.R. Williams, H. Ohno CCR6hiCD11c(int) B cells promote M-cell differentiation in Peyer's patch, Int Immunol. 23 (2011) 261-269.

[58] A. Kobayashi, D.S. Donaldson, C. Erridge, T. Kanaya, I.R. Williams, H. Ohno, A Mahajan, N.A. Mabbott, The functional maturation of M cells is dramatically reduced in the Peyer's patches of aged mice, Mucosal Immunol. 6 (2013) 1027-1037.

[59] S. Westphal, A. Lugering J. von Wedel, C. von Eiff, C. Maaser, T. Spahn, G. Heusipp, M.A. Schmidt, H. Herbst, I.R. Williams, W. Domschke, T. Kucharzik, Resistance of chemokine receptor 6-deficient mice to Yersinia enterocolitica infection: evidence of defective M-cell formation in vivo, Am. J. Pathol. 172 (2008) 671-680.

[60] J.H. Rand, X.X. Wu, E.Y. Lin, A. Griffel, P. Gialanella, J.C. McKitrick, Annexin A5 binds to lipopolysaccharide and reduces its endotoxin activity, mBio 3 (2012).

[61] K.A. Kadaoui, B. Corthesy, Secretory IgA mediates bacterial translocation to dendritic cells in mouse Peyer's patches with restriction to mucosal compartment J. Immunol. 179 (2007) 7751-7757.

[62] J. Rey, N. Garin, F. Spertini, B. Corthesy, Targeting of secretory IgA to Peyer's patch dendritic and T cells after transport by intestinal M cells, J. Immunol. 172 (2004) 3026-3033.

[63] N. Rochereau, D. Drocourt, E. Perouzel, V. Pavot, P. Redelinghuys, G.D. Brown, G Tiraby, X. Roblin, B. Verrier, C. Genin, B. Corthesy, S. Paul, Dectin-1 is essential for reverse transcytosis of glycosylated SIgA-antigen complexes by intestinal M cells, PLoS Biol. 11 (2013) e1001658.

[64] S. Halle, D. Bumann, H. Herbrand, Y. Willer, S. Dahne, R. Forster, O. Pabst, Solitary intestinal lymphoid tissue provides a productive port of entry for Salmonella enterica serovar Typhimurium, Infect. Immun. 75 (2007) 1577-1585.

[65] C. Martinoli, A. Chiavelli, M. Rescigno, Entry route of Salmonella typhimurium directs the type of induced immune response, Immunity 27 (2007) 975-984

[66] K. Suzuki, B. Meek, Y. Doi, T. Honjo, S. Fagarasan, Two distinctive pathways for recruitment of naive and primed $\operatorname{IgM}+\mathrm{B}$ cells to the gut lamina propria, Proc. Natl. Acad. Sci. U. S. A. 102 (2005) 2482-2486.

[67] M. Tsuji, K. Suzuki, H. Kitamura, M. Maruya, K. Kinoshita, I.I. Ivanov, K. Itoh, D.R Littman, S. Fagarasan, Requirement for lymphoid tissue-inducer cells in isolated follicle formation and $\mathrm{T}$ cell-independent immunoglobulin A generation in the gut, Immunity 29 (2008) 261-271

[68] C. King, S.G. Tangye, C.R. Mackay, T follicular helper (TFH) cells in normal and dysregulated immune responses, Annu. Rev. Immunol. 26 (2008) 741-766.

[69] A.J. Macpherson, T. Uhr, Induction of protective IgA by intestinal dendritic cells carrying commensal bacteria, Science 303 (2004) 1662-1665.

[70] A. Iwasaki, B.L. Kelsall, Freshly isolated Peyer's patch, but not spleen, dendritic cells produce interleukin 10 and induce the differentiation of T helper type 2 cells, J. Exp. Med. 190 (1999) 229-239.

[71] J.R. Mora, M. Iwata, B. Eksteen, S.Y. Song, T. Junt, B. Senman, K.L. Otipoby, A. Yokota H. Takeuchi, P. Ricciardi-Castagnoli, K. Rajewsky, D.H. Adams, U.H. von Andrian, Generation of gut-homing IgA-secreting B cells by intestinal dendritic cells, Science 314 (2006) 1157-1160.

[72] A. Sato, M. Hashiguchi, E. Toda, A. Iwasaki, S. Hachimura, S. Kaminogawa, CD11b + Peyer's patch dendritic cells secrete IL-6 and induce IgA secretion from naive B cells, J. Immunol. 171 (2003) 3684-3690

[73] D.T. Ruane, E.C. Lavelle, The role of CD103(+) dendritic cells in the intestinal mucosal immune system, Front. Immunol. 2 (2011) 25

[74] O. Schulz, E. Jaensson, E.K. Persson, X. Liu, T. Worbs, W.W. Agace, O. Pabst, Intestinal CD103 +, but not CX3CR1 +, antigen sampling cells migrate in lymph and serve classical dendritic cell functions, J. Exp. Med. 206 (2009) 3101-3114.

[75] Y. Lin, S.R. Slight, S.A. Khader, Th17 cytokines and vaccine-induced immunity, Semin. Immunopathol. 32 (2010) 79-90.

[76] H.R. Cha, H.J. Ko, E.D. Kim, S.Y. Chang, S.U. Seo, N. Cuburu, S. Ryu, S. Kim, M.N. Kweon, Mucosa-associated epithelial chemokine/CCL28 expression in the uterus attracts CCR10 + IgA plasma cells following mucosal vaccination via estrogen control, J. Immunol. 187 (2011) 3044-3052.

[77] C.L. Scott, A.M. Aumeunier, A.M. Mowat, Intestinal CD103 + dendritic cells: master regulators of tolerance? Trends Immunol. 32 (2011) 412-419.

[78] M. Semmrich, M. Plantinga, M. Svensson-Frej, H. Uronen-Hansson, T. Gustafsson, A.M. Mowat, U. Yrlid, B.N. Lambrecht, W.W. Agace, Directed antigen targeting in vivo identifies a role for CD103 + dendritic cells in both tolerogenic and immunogenic T-cell responses, Mucosal Immunol. 5 (2012) 150-160.

[79] D. Ruane, L. Brane, B.S. Reis, C. Cheong, J. Poles, Y. Do, H. Zhu, K. Velinzon, J.H. Choi, N. Studt, L. Mayer, E.C. Lavelle, R.M. Steinman, D. Mucida, S. Mehandru, Lung dendritic cells induce migration of protective $\mathrm{T}$ cells to the gastrointestinal tract, J. Exp. Med. 210 (2013) 1871-1888.

[80] M.L. del Rio, G. Bernhardt, J.I. Rodriguez-Barbosa, R. Forster, Development and functional specialization of CD103 + dendritic cells, Immunol. Rev. 234 (2010) 268-281.

[81] J.R. Mora, U.H. von Andrian, Differentiation and homing of IgA-secreting cells, Mucosal Immunol. 1 (2008) 96-109.

82] N. Feng, M.C. Jaimes, N.H. Lazarus, D. Monak, C. Zhang, E.C. Butcher, H.B. Greenberg, Redundant role of chemokines CCL25/TECK and CCL28/MEC in IgA + plasmablast recruitment to the intestinal lamina propria after rotavirus infection, J. Immunol. 176 (2006) 5749-5759.

[83] B.S. Sheridan, L. Lefrancois, Regional and mucosal memory T cells, Nat. Immunol. 12 (2011) 485-491.

[84] J.R. Mora, U.H. von Andrian, Role of retinoic acid in the imprinting of gut-homing IgA-secreting cells, Semin. Immunol. 21 (2009) 28-35.

[85] H. Kiyono, S. Fukuyama, NALT- versus Peyer's-patch-mediated mucosal immunity, Nat. Rev. Immunol. 4 (2004) 699-710.

[86] P. Brandtzaeg, Function of mucosa-associated lymphoid tissue in antibody formation, Immunol. Invest. 39 (2010) 303-355

[87] M.J. Bevan, Memory T cells as an occupying force, Eur. J. Immunol. 41 (2011) 1192-1195.

[88] C. Blaschitz, M. Raffatellu, Th17 cytokines and the gut mucosal barrier, J. Clin. Immunol. 30 (2010) 196-203.

[89] T. Feng, C.O. Elson, Adaptive immunity in the host-microbiota dialog, Mucosal Immunol. 4 (2011) 15-21.

[90] A.J. Macpherson, K.D. McCoy, F.E. Johansen, P. Brandtzaeg, The immune geography of IgA induction and function, Mucosal Immunol. 1 (2008) 11-22.

[91] C.S. Kaetzel, The polymeric immunoglobulin receptor: bridging innate and adaptive immune responses at mucosal surfaces, Immunol. Rev. 206 (2005) 83-99.

[92] M. Kilian, J. Reinholdt, H. Lomholt, K. Poulsen, E.V. Frandsen, Biological significance of IgA1 proteases in bacterial colonization and pathogenesis: critical evaluation of experimental evidence, APMIS 104 (1996) 321-338.

[93] N.J. Mantis, S.J. Forbes, Secretory IgA: arresting microbial pathogens at epithelial borders, Immunol. Invest. 39 (2010) 383-406.

[94] P. Brandtzaeg, Induction of secretory immunity and memory at mucosal surfaces, Vaccine 25 (2007) 5467-5484.

[95] O. Pabst, New concepts in the generation and functions of IgA, Nat. Rev. Immunol. 12 (2012) 821-832

[96] N.W. Palm, M.R. de Zoete, T.W. Cullen, N.A. Barry, J. Stefanowski, L. Hao, P.H. Degnan, J. Hu, I. Peter, W. Zhang, E. Ruggiero, J.H. Cho, A.L. Goodman, R.A. Flavell, Immunoglobulin A coating identifies colitogenic bacteria in inflammatory bowel disease, Cell 158 (2014) 1000-1010.

[97] N.L. Harris, I. Spoerri, J.F. Schopfer, C. Nembrini, P. Merky, J. Massacand, J.F. Urban Jr., A. Lamarre, K. Burki, B. Odermatt, R.M. Zinkernagel, A.J. Macpherson, Mechanisms of neonatal mucosal antibody protection, J. Immunol. 177 (2006) 6256-6262.

[98] D. Tokuhara, Y. Yuki, T. Nochi, T. Kodama, M. Mejima, S. Kurokawa, Y. Takahashi, M. Nanno, U. Nakanishi, F. Takaiwa, T. Honda, H. Kiyono, Secretory IgA-mediated protection against $V$. cholerae and heat-labile enterotoxin-producing enterotoxigenic Escherichia coli by rice-based vaccine, Proc. Natl. Acad. Sci. U. S. A. 107 (2010) 8794-8799.

[99] J. Sanchez, J. Holmgren, Virulence factors, pathogenesis and vaccine protection in cholera and ETEC diarrhea, Curr. Opin. Immunol. 17 (2005) 388-398.

[100] P.L. Ogra, H. Faden, R.C. Welliver, Vaccination strategies for mucosal immune responses, Clin. Microbiol. Rev. 14 (2001) 430-445.

[101] J. Holmgren, L. Bourgeois, N. Carlin, J. Clements, B. Gustafsson, A. Lundgren, E. Nygren, J. Tobias, R. Walker, A.M. Svennerholm, Development and preclinical evaluation of safety and immunogenicity of an oral ETEC vaccine containing inactivated $\mathrm{E}$. coli bacteria overexpressing colonization factors CFA/I, CS3, CS5 and CS6 combined with a hybrid LT/CT B subunit antigen, administered alone and together with dmLT adjuvant, Vaccine 31 (2013) 2457-2464.

[102] A. Lundgren, S. Leach, J. Tobias, N. Carlin, B. Gustafsson, M. Jertborn, L. Bourgeois, R. Walker, J. Holmgren, A.M. Svennerholm, Clinical trial to evaluate safety and immunogenicity of an oral inactivated enterotoxigenic Escherichia coli prototype vaccine containing CFA/I overexpressing bacteria and recombinantly produced LTB/CTB hybrid protein, Vaccine 31 (2013) 1163-1170.

[103] J. Tobias, M. Lebens, I. Bolin, G. Wiklund, A.M. Svennerholm, Construction of non-toxic Escherichia coli and Vibrio cholerae strains expressing high and immunogenic levels of enterotoxigenic E. coli colonization factor I fimbriae, Vaccine 26 (2008) 743-752.

[104] S.L. Karlsson, E. Ax, E. Nygren, S. Kallgard, M. Blomquist, A. Ekman, J. Benktander, J. Holmgren, M. Lebens, Development of Stable Vibrio cholerae 01 Hikojima Type Vaccine Strains Co-Expressing the Inaba and Ogawa Lipopolysaccharide Antigens, PLoS ONE 9 (2014) e108521.

[105] W. Nieves, H. Petersen, B.M. Judy, C.A. Blumentritt, K. Russell-Lodrigue, C.J. Roy, A.G. Torres, L.A. Morici, A Burkholderia pseudomallei outer membrane vesicle vaccine provides protection against lethal sepsis, Clin. Vaccine Immunol. 21 (2014) 747-754. 
[106] H. Petersen, W. Nieves, K. Russell-Lodrigue, C.J. Roy, L.A. Morici, Evaluation of a Outer Membrane Vesicle Vaccine in Nonhuman Primates, Procedia Vaccinol. 8 (2014) 38-42.

[107] R. Acevedo, S. Fernandez, C. Zayas, A. Acosta, M.E. Sarmiento, V.A. Ferro, E. Rosenqvist, C. Campa, D. Cardoso, L. Garcia, J.L. Perez, Bacterial outer membrane vesicles and vaccine applications, Front. Immunol. 5 (2014) 121.

[108] S.K. Datta, M. Sabet, K.P. Nguyen, P.A. Valdez, J.M. Gonzalez-Navajas, S. Islam, I. Mihajlov, J. Fierer, P.A. Insel, N.J. Webster, D.G. Guiney, E. Raz, Mucosal adjuvant activity of cholera toxin requires Th17 cells and protects against inhalation anthrax, Proc. Natl. Acad. Sci. U. S. A. 107 (2010) 10638-10643.

[109] Z. Kuate Defo, B. Lee, New approaches in oral rotavirus vaccines, Crit. Rev. Microbiol. (2014) 1-11.

[110] L.H. Lua, N.K. Connors, F. Sainsbury, Y.P. Chuan, N. Wibowo, A.P. Middelberg, Bioengineering virus-like particles as vaccines, Biotechnol. Bioeng. 111 (2014) 425-440.

[111] W.I. Lencer, T.R. Hirst, R.K. Holmes, Membrane traffic and the cellular uptake of cholera toxin, Biochim. Biophys. Acta 1450 (1999) 177-190.

[112] J. Clemens, S. Shin, D. Sur, G.B. Nair, J. Holmgren, New-generation vaccines against cholera, Nat. Rev. Gastroenterol. Hepatol. 8 (2011) 701-710.

[113] L.C. Freytag, J.D. Clements, D.G. Eliasson, N. Lycke, Use of genetically or chemically detoxified mutants of cholera and Escherichia coli heat-labile enterotoxins as mucosal adjuvants, New generation vaccines, 2010, pp. 273-283.

[114] B.D. Spangler, Structure and function of cholera toxin and the related Escherichia coli heat-labile enterotoxin, Microbiol. Rev. 56 (1992) 622-647.

[115] D.P. Snider, The mucosal adjuvant activities of ADP-ribosylating bacterial enterotoxins, Crit. Rev. Immunol. 15 (1995) 317-348.

[116] A. Azizi, H. Ghunaim, F. Diaz-Mitoma, J. Mestecky, Mucosal HIV vaccines: a holy grail or a dud? Vaccine 28 (2010) 4015-4026.

[117] A.K. Gloudemans, M. Plantinga, M. Guilliams, M.A. Willart, A. Ozir-Fazalalikhan, A. van der Ham, L. Boon, N.L. Harris, H. Hammad, H.C. Hoogsteden, M. Yazdanbakhsh, R.W. Hendriks, B.N. Lambrecht, H.H. Smits, The mucosal adjuvant cholera toxin B instructs non-mucosal dendritic cells to promote IgA production via retinoic acid and TGF-beta, PLoS ONE 8 (2013) e59822.

[118] H.H. Smits, A.K. Gloudemans, M. van Nimwegen, M.A. Willart, T. Soullie, F. Muskens, E.C. de Jong, L. Boon, C. Pilette, F.E. Johansen, H.C. Hoogsteden, H. Hammad, B.N. Lambrecht, Cholera toxin B suppresses allergic inflammation through induction of secretory IgA, Mucosal Immunol. 2 (2009) 331-339.

[119] R. Glueck, Pre-clinical and clinical investigation of the safety of a novel adjuvant for intranasal immunization, Vaccine 20 (Suppl. 1) (2001) S42-S44.

[120] K. Fujihashi, T. Koga, F.W. van Ginkel, Y. Hagiwara, J.R. McGhee, A dilemma for mucosal vaccination: efficacy versus toxicity using enterotoxin-based adjuvants, Vaccine 20 (2002) 2431-2438.

[121] M. Mutsch, W. Zhou, P. Rhodes, M. Bopp, R.T. Chen, T. Linder, C. Spyr, R. Steffen, Use of the inactivated intranasal influenza vaccine and the risk of Bell's palsy in Switzerland, N. Engl. J. Med. 350 (2004) 896-903.

[122] M. Pizza, M.M. Giuliani, M.R. Fontana, E. Monaci, G. Douce, G. Dougan, K.H. Mills, R. Rappuoli, G. Del Giudice, Mucosal vaccines: non toxic derivatives of LT and CT as mucosal adjuvants, Vaccine 19 (2001) 2534-2541.

[123] C.F. Brereton, C.E. Sutton, P.J. Ross, Y. Iwakura, M. Pizza, R. Rappuoli, E.C. Lavelle, K.H. Mills, Escherichia coli heat-labile enterotoxin promotes protective Th17 responses against infection by driving innate IL-1 and IL-23 production, J. Immunol. 186 (2011) 5896-5906.

[124] E.J. Ryan, E. McNeela, G.A. Murphy, H. Stewart, D. O'Hagan, M. Pizza, R. Rappuoli, K.H. Mills, Mutants of Escherichia coli heat-labile toxin act as effective mucosal adjuvants for nasal delivery of an acellular pertussis vaccine: differential effects of the nontoxic $A B$ complex and enzyme activity on Th1 and Th2 cells, Infect. Immun. 67 (1999) 6270-6280.

[125] H. Jakobsen, D. Schulz, M. Pizza, R. Rappuoli, I. Jonsdottir, Intranasal immunization with pneumococcal polysaccharide conjugate vaccines with nontoxic mutants of Escherichia coli heat-labile enterotoxins as adjuvants protects mice against invasive pneumococcal infections, Infect. Immun. 67 (1999) 5892-5897.

[126] J.A. Neidleman, M. Vajdy, M. Ugozzoli, G. Ott, D. O'Hagan, Genetically detoxified mutants of heat-labile enterotoxin from Escherichia coli are effective adjuvants for induction of cytotoxic T-cell responses against HIV-1 gag-p55, Immunology 101 (2000) 154-160.

[127] D.J. Lewis, Z. Huo, S. Barnett, I. Kromann, R. Giemza, E. Galiza, M. Woodrow, B. Thierry-Carstensen, P. Andersen, D. Novicki, G. Del Giudice, R. Rappuoli, Transient facial nerve paralysis (Bell's palsy) following intranasal delivery of a genetically detoxified mutant of Escherichia coli heat labile toxin, PLoS ONE 4 (2009) e6999.

[128] S. Leach, J.D. Clements, J. Kaim, A. Lundgren, The adjuvant double mutant Escherichia coli heat labile toxin enhances IL-17A production in human T cells specific for bacterial vaccine antigens, PLoS ONE 7 (2012) e51718.

[129] L. Sjokvist Ottsjo, C.F. Flach, J. Clements, J. Holmgren, S. Raghavan, A double mutant heat-labile toxin from Escherichia coli, LT(R192G/L211A), is an effective mucosal adjuvant for vaccination against Helicobacter pylori infection, Infect. Immun. 81 (2013) 1532-1540.

[130] A. Lundgren, L. Bourgeois, N. Carlin, J. Clements, B. Gustafsson, M. Hartford, J. Holmgren, M. Petzold, R. Walker, A.M. Svennerholm, Safety and immunogenicity of an improved oral inactivated multivalent enterotoxigenic Escherichia coli (ETEC) vaccine administered alone and together with dmLT adjuvant in a doubleblind, randomized, placebo-controlled Phase I study, Vaccine 32 (2014) 7077-7084.

[131] L.C. Agren, L. Ekman, B. Lowenadler, N.Y. Lycke, Genetically engineered nontoxic vaccine adjuvant that combines B cell targeting with immunomodulation by cholera toxin A1 subunit, J. Immunol. 158 (1997) 3936-3946.

[132] N. Lycke, M. Bemark, Mucosal adjuvants and long-term memory development with special focus on CTA1-DD and other ADP-ribosylating toxins, Mucosal Immunol. 3 (2010) 556-566.
[133] A.M. Eriksson, K.M. Schon, N.Y. Lycke, The cholera toxin-derived CTA1-DD vaccine adjuvant administered intranasally does not cause inflammation or accumulate in the nervous tissues, J. Immunol. 173 (2004) 3310-3319.

[134] C. Sundling, K. Schon, A. Morner, M.N. Forsell, R.T. Wyatt, R. Thorstensson, G.B. Karlsson Hedestam, N.Y. Lycke, CTA1-DD adjuvant promotes strong immunity against human immunodeficiency virus type 1 envelope glycoproteins following mucosal immunization, J. Gen. Virol. 89 (2008) 2954-2964.

[135] A.E. Abautret-Daly, C.J. Davitt, E.C. Lavelle, Harnessing the antibacterial and immunological properties of Mucosal-associated invariant T cells in the development of nove oral vaccines against enteric infections, Biochem. Pharmacol. 92 (2014) 173-183.

[136] V. Cerundolo, P. Barral, F.D. Batista, Synthetic iNKT cell-agonists as vaccine adjuvants-finding the balance, Curr. Opin. Immunol. 22 (2010) 417-424.

[137] W. Lu, S. Chen, C. Lai, W. Guo, L. Fu, J.M. Andrieu, Induction of CD8 + regulatory T cells protects macaques against SIV challenge, Cell Rep. 2 (2012) 1736-1746.

[138] D.T. O'Hagan, G.S. Ott, E. De Gregorio, A. Seubert, The mechanism of action of MF59 - an innately attractive adjuvant formulation, Vaccine 30 (2012) 4341-4348.

[139] K. Kataoka, A. Harada, Y. Nagasaki, Block copolymer micelles for drug delivery: design, characterization and biological significance, Adv. Drug Deliv. Rev. 47 (2001) 113-131.

[140] M. Henriksen-Lacey, K.S. Korsholm, P. Andersen, Y. Perrie, D. Christensen, Liposoma vaccine delivery systems, Expert Opin. Drug Deliv. 8 (2011) 505-519.

[141] S.T. Agnandji, B. Lell, S.S. Soulanoudjingar, J.F. Fernandes, B.P. Abossolo, C. Conzelmann, B.G. Methogo, Y. Doucka, A. Flamen, B. Mordmuller, S. Issifou, P.G. Kremsner, J. Sacarlal, P. Aide, M. Lanaspa, J.J. Aponte, A. Nhamuave, D. Quelhas, Q. Bassat, S. Mandjate, E. Macete, P. Alonso, S. Abdulla, N. Salim, O. Juma, M. Shomari, K. Shubis, F. Machera, A.S. Hamad, R. Minja, A. Mtoro, A. Sykes, S. Ahmed, A.M. Urassa, A.M. Ali, G. Mwangoka, M. Tanner, H. Tinto, U. D'Alessandro, H. Sorgho, I. Valea, M.C. Tahita, W. Kabore, S. Ouedraogo, Y. Sandrine, R.T. Guiguemde, J.B. Ouedraogo, M.J. Hamel, S. Kariuki, C. Odero, M. Oneko, K. Otieno, N. Awino, J. Omoto, J. Williamson, V. Muturi-Kioi, K.F. Laserson, L. Slutsker, W. Otieno, L. Otieno, O. Nekoye, S. Gondi, A. Otieno, B. Ogutu, R. Wasuna, V. Owira, D. Jones, A.A. Onyango, P. Njuguna, R. Chilengi, P. Akoo, C. Kerubo, J. Gitaka, C. Maingi, T. Lang, A. Olotu, B. Tsofa, P. Bejon, N. Peshu, K. Marsh, S. Owusu-Agyei, K.P. Asante, K. Osei-Kwakye, O. Boahen, S. Ayamba, K. Kayan, R. Owusu-Ofori, D. Dosoo, I. Asante, G. Adjei, G. Adjei, D. Chandramohan, B. Greenwood, J. Lusingu, S. Gesase, A. Malabeja, O. Abdul, H. Kilavo, C. Mahende, E. Liheluka, M. Lemnge, T. Theander, C. Drakeley, D. Ansong, T. Agbenyega, S. Adjei, H.O. Boateng, T. Rettig, J. Bawa, J. Sylverken, D. Sambian, A. Agyekum, L. Owusu, F. Martinson, I. Hoffman, T. Mvalo, P. Kamthunzi, R. Nkomo, A. Msika, A. Jumbe, N. Chome, D. Nyakuipa, J. Chintedza, W.R. Ballou, M. Bruls, J. Cohen, Y. Guerra, E. Jongert, D. Lapierre, A. Leach, M. Lievens, O. Ofori-Anyinam, J. Vekemans, T. Carter, D. Leboulleux, C. Loucq, A. Radford, B. Savarese, D. Schellenberg, M. Sillman, P. Vansadia, S.C.T.P. Rts, First results of phase 3 trial of RTS, S/AS01 malaria vaccine in African children, N. Engl. J. Med. 365 (2011) 1863-1875.

[142] V.A. Stewart, S.M. McGrath, D.S. Walsh, S. Davis, A.S. Hess, L.A. Ware, K.E. Kester, J.F. Cummings, J.R. Burge, G. Voss, M. Delchambre, N. Garcon, D.B. Tang, J.D. Cohen, D.G. Heppner Jr., Pre-clinical evaluation of new adjuvant formulations to improve the immunogenicity of the malaria vaccine RTS, S/AS02A, Vaccine 24 (2006) 6483-6492.

[143] A.C. Silva, D. Santos, D. Ferreira, C.M. Lopes, Lipid-based nanocarriers as an alternative for oral delivery of poorly water- soluble drugs: peroral and mucosal routes, Curr. Med. Chem. 19 (2012) 4495-4510.

[144] T. Nakanishi, J. Kunisawa, A. Hayashi, Y. Tsutsumi, K. Kubo, S. Nakagawa, M. Nakanishi, K. Tanaka, T. Mayumi, Positively charged liposome functions as an efficient immunoadjuvant in inducing cell-mediated immune response to soluble proteins, J. Control. Release 61 (1999) 233-240.

[145] C. Foged, C. Arigita, A. Sundblad, W. Jiskoot, G. Storm, S. Frokjaer, Interaction of dendritic cells with antigen-containing liposomes: effect of bilayer composition, Vaccine 22 (2004) 1903-1913.

[146] X. Wei, B. Shao, Z. He, T. Ye, M. Luo, Y. Sang, X. Liang, W. Wang, S. Luo, S. Yang, S. Zhang, C. Gong, M. Gou, H. Deng, Y. Zhao, H. Yang, S. Deng, C. Zhao, L. Yang, Z Qian, J. Li, X. Sun, J. Han, C. Jiang, M. Wu, Z. Zhang, Cationic nanocarriers induce cell necrosis through impairment of $\mathrm{Na}(+) / \mathrm{K}(+)$-ATPase and cause subsequent inflammatory response, Cell Res. 25 (2015) 237-253.

[147] E.M. Agger, I. Rosenkrands, J. Hansen, K. Brahimi, B.S. Vandahl, C. Aagaard, K Werninghaus, C. Kirschning, R. Lang, D. Christensen, M. Theisen, F. Follmann, P. Andersen, Cationic liposomes formulated with synthetic mycobacterial cordfactor (CAF01): a versatile adjuvant for vaccines with different immunological requirements, PLoS ONE 3 (2008) e3116.

[148] G.J. Gram, I. Karlsson, E.M. Agger, P. Andersen, A. Fomsgaard, A novel liposome-based adjuvant CAF01 for induction of CD8 $(+$ ) cytotoxic T-lymphocytes (CTL) to HIV-1 minimal CTL peptides in HLA-A*0201 transgenic mice, PLoS ONE 4 (2009) e6950.

[149] A.T. Kamath, A.F. Rochat, D. Christensen, E.M. Agger, P. Andersen, P.H. Lambert, C.A. Siegrist, A liposome-based mycobacterial vaccine induces potent adult and neonatal multifunctional T cells through the exquisite targeting of dendritic cells, PLoS ONE 4 (2009) e5771.

[150] J. Hansen, K.T. Jensen, F. Follmann, E.M. Agger, M. Theisen, P. Andersen, Liposome delivery of Chlamydia muridarum major outer membrane protein primes a Th1 response that protects against genital chlamydial infection in a mouse model, J. Infect. Dis. 198 (2008) 758-767.

[151] D. Christensen, C. Foged, I. Rosenkrands, C.V. Lundberg, P. Andersen, E.M. Agger H.M. Nielsen, CAF01 liposomes as a mucosal vaccine adjuvant: In vitro and in vivo investigations, Int. J. Pharm. 390 (2010) 19-24.

[152] A. Henderson, K. Propst, R. Kedl, S. Dow, Mucosal immunization with liposomenucleic acid adjuvants generates effective humoral and cellular immunity, Vaccine 29 (2011) 5304-5312. 
153] T. Nakanishi, A. Hayashi, J. Kunisawa, Y. Tsutsumi, K. Tanaka, Y. Yashiro-Ohtani, M. Nakanishi, H. Fujiwara, T. Hamaoka, T. Mayumi, Fusogenic liposomes efficiently deliver exogenous antigen through the cytoplasm into the MHC class I processing pathway, Eur. J. Immunol. 30 (2000) 1740-1747.

[154] Y. Tanaka, M. Taneichi, M. Kasai, T. Kakiuchi, T. Uchida, Liposome-coupled antigens are internalized by antigen-presenting cells via pinocytosis and cross-presented to CD8 T cells, PLoS ONE 5 (2010) e15225.

[155] H. Chen, V. Torchilin, R. Langer, Lectin-bearing polymerized liposomes as potential oral vaccine carriers, Pharm. Res. 13 (1996) 1378-1383.

[156] N. Venkatesan, S.P. Vyas, Polysaccharide coated liposomes for oral immunizationdevelopment and characterization, Int. J. Pharm. 203 (2000) 169-177.

[157] D.T. O'Hagan, E. De Gregorio, The path to a successful vaccine adjuvant-'the long and winding road', Drug Discov. Today 14 (2009) 541-551.

[158] J.C. Cox, A. Sjolander, I.G. Barr, ISCOMs and other saponin based adjuvants, Adv. Drug Deliv. Rev. 32 (1998) 247-271.

[159] A. Sjolander, J.C. Cox, I.G. Barr, ISCOMs: an adjuvant with multiple functions, J. Leukoc. Biol. 64 (1998) 713-723.

[160] W.T. McBurney, D.G. Lendemans, J. Myschik, T. Hennessy, T. Rades, S. Hook, In vivo activity of cationic immune stimulating complexes (PLUSCOMs), Vaccine 26 (2008) 4549-4556.

[161] A. Schiott, K. Larsson, S. Manniche, S. Kalliomaki, A.V. Heydenreich, K. Dalsgaard, N. Kirkby, Posintro-HBsAg, a modified ISCOM including HBsAg, induces strong cellular and humoral responses, Int. J. Pharm. 414 (2011) 312-320.

[162] D.G. Eliasson, A. Helgeby, K. Schon, C. Nygren, K. El-Bakkouri, W. Fiers, X. Saelens K.B. Lovgren, I. Nystrom, N.Y. Lycke, A novel non-toxic combined CTA1-DD and ISCOMS adjuvant vector for effective mucosal immunization against influenza virus, Vaccine 29 (2011) 3951-3961

[163] A. Aguila, A.M. Donachie, M. Peyre, C.P. McSharry, D. Sesardic, A.M. Mowat, Induction of protective and mucosal immunity against diphtheria by a immune stimulating complex (ISCOMS) based vaccine, Vaccine 24 (2006) 5201-5210.

[164] C.S. Andersen, J. Dietrich, E.M. Agger, N.Y. Lycke, K. Lovgren, P. Andersen, The combined CTA1-DD/ISCOMs vector is an effective intranasal adjuvant for boosting prior Mycobacterium bovis BCG immunity to Mycobacterium tuberculosis, Infect. Immun. 75 (2007) 408-416

[165] A. Roldao, M.C. Mellado, L.R. Castilho, M.J. Carrondo, P.M. Alves, Virus-like particles in vaccine development, Expert Rev. Vaccines 9 (2010) 1149-1176.

[166] S.M. Kingsman, A.J. Kingsman, Polyvalent recombinant antigens: a new vaccine strategy, Vaccine 6 (1988) 304-306.

[167] A. Zeltins, Construction and characterization of virus-like particles: a review, Mol. Biotechnol. 53 (2013) 92-107.

[168] K.R. Young, S.P. McBurney, L.U. Karkhanis, T.M. Ross, Virus-like particles: designing an effective AIDS vaccine, Methods 40 (2006) 98-117.

[169] P. Maurer, G.T. Jennings, J. Willers, F. Rohner, Y. Lindman, K. Roubicek, W.A. Renner, P. Muller, M.F. Bachmann, A therapeutic vaccine for nicotine dependence: preclinical efficacy, and Phase I safety and immunogenicity, Eur. J. Immunol. 35 (2005) 2031-2040.

[170] K.G. Patel, J.R. Swartz, Surface functionalization of virus-like particles by direct conjugation using azide-alkyne click chemistry, Bioconjug. Chem. 22 (2011) 376-387.

[171] E. Strable, M.G. Finn, Chemical modification of viruses and virus-like particles, Curr. Top. Microbiol. Immunol. 327 (2009) 1-21.

[172] C.M. Wheeler, S.K. Kjaer, K. Sigurdsson, O.E. Iversen, M. Hernandez-Avila, G. Perez D.R. Brown, L.A. Koutsky, E.H. Tay, P. Garcia, K.A. Ault, S.M. Garland, S. Leodolter S.E. Olsson, G.W. Tang, D.G. Ferris, J. Paavonen, M. Steben, F.X. Bosch, J. Dillner, E.A. Joura, R.J. Kurman, S. Majewski, N. Munoz, E.R. Myers, L.L. Villa, F.J. Taddeo, C. Roberts, A. Tadesse, J. Bryan, L.C. Lupinacci, K.E. Giacoletti, M. James, S Vuocolo, T.M. Hesley, E. Barr, The impact of quadrivalent human papillomavirus (HPV; types 6, 11, 16, and 18) L1 virus-like particle vaccine on infection and disease due to oncogenic nonvaccine HPV types in sexually active women aged 16-26 years, J. Infect. Dis. 199 (2009) 936-944.

[173] R.S. Lowe, D.R. Brown, J.T. Bryan, J.C. Cook, H.A. George, K.J. Hofmann, W.M. Hurni, J.G. Joyce, E.D. Lehman, H.Z. Markus, M.P. Neeper, L.D. Schultz, A.R. Shaw, K.U. Jansen, Human papillomavirus type 11 (HPV-11) neutralizing antibodies in the serum and genital mucosal secretions of African green monkeys immunized with HPV-11 virus-like particles expressed in yeast, J. Infect. Dis. 176 (1997) $1141-1145$

[174] K.U. Jansen, A.R. Shaw, Human papillomavirus vaccines and prevention of cervical cancer, Annu. Rev. Med. 55 (2004) 319-331.

[175] M. Stanley, D.R. Lowy, I. Frazer, Chapter 12: Prophylactic HPV vaccines: underlying mechanisms, Vaccine 24 (Suppl. 3) (2006) 106-113 (S3).

[176] D. Felnerova, J.F. Viret, R. Gluck, C. Moser, Liposomes and virosomes as delivery systems for antigens, nucleic acids and drugs, Curr. Opin. Biotechnol. 15 (2004) 518-529.

[177] R. Gluck, Immunopotentiating reconstituted influenza virosomes (IRIVs) and other adjuvants for improved presentation of small antigens, Vaccine 10 (1992) 915-919.

[178] R. Gluck, R. Mischler, B. Finkel, J.U. Que, B. Scarpa, S.J. Cryz Jr., Immunogenicity of new virosome influenza vaccine in elderly people, Lancet 344 (1994) 160-163.

[179] R. Mischler, I.C. Metcalfe, Inflexal V a trivalent virosome subunit influenza vaccine: production, Vaccine 20 (Suppl. 5) (2002) B17-B23.

[180] R. Zurbriggen, I. Novak-Hofer, A. Seelig, R. Gluck, IRIV-adjuvanted hepatitis A vaccine: in vivo absorption and biophysical characterization, Prog. Lipid Res. 39 (2000) 3-18.

[181] M. Bomsel, D. Tudor, A.S. Drillet, A. Alfsen, Y. Ganor, M.G. Roger, N. Mouz, M. Amacker, A. Chalifour, L. Diomede, G. Devillier, Z. Cong, Q. Wei, H. Gao, C. Qin, G.B. Yang, R. Zurbriggen, L. Lopalco, S. Fleury, Immunization with HIV-1 gp41 subunit virosomes induces mucosal antibodies protecting nonhuman primates against vaginal SHIV challenges, Immunity 34 (2011) 269-280.
[182] M.M. Herbst-Kralovetz, Overcoming barriers in the mucosal delivery of virus-like particle-based vaccines, Ther. Deliv. 5 (2014) 741-744.

[183] C. Moser, M. Amacker, A.R. Kammer, S. Rasi, N. Westerfeld, R. Zurbriggen, Influenza virosomes as a combined vaccine carrier and adjuvant system for prophylactic and therapeutic immunizations, Expert Rev. Vaccines 6 (2007) 711-721.

[184] B.E. Hjelm, J. Kilbourne, M.M. Herbst-Kralovetz, TLR7 and 9 agonists are highly effective mucosal adjuvants for norovirus virus-like particle vaccines, Hum. Vaccines Immunother. 10 (2014) 410-416.

[185] E.M. Jackson, M.M. Herbst-Kralovetz, Intranasal vaccination with murabutide enhances humoral and mucosal immune responses to a virus-like particle vaccine, PLoS ONE 7 (2012) e41529.

[186] A. des Rieux, V. Fievez, M. Garinot, Y.J. Schneider, V. Preat, Nanoparticles as potential oral delivery systems of proteins and vaccines: a mechanistic approach, J. Control. Release 116 (2006) 1-27.

[187] L.M. Ensign, R. Cone, J. Hanes, Oral drug delivery with polymeric nanoparticles: the gastrointestinal mucus barriers, Adv. Drug Deliv. Rev. 64 (2012) 557-570.

[188] A.E. Gregory, R. Titball, D. Williamson, Vaccine delivery using nanoparticles, Front. Cell. Infect. Microbiol. 3 (2013) 13.

[189] V.E. Schijns, Immunological concepts of vaccine adjuvant activity, Curr. Opin. Immunol. 12 (2000) 456-463.

[190] D.J. Brayden, A.W. Baird, Microparticle vaccine approaches to stimulate mucosal immunisation, Microbes Infect. 3 (2001) 867-876.

[191] S.K. Lai, Y.Y. Wang, K. Hida, R. Cone, J. Hanes, Nanoparticles reveal that human cervicovaginal mucus is riddled with pores larger than viruses, Proc. Natl. Acad. Sci. U. S. A. 107 (2010) 598-603.

[192] J.J. Reineke, D.Y. Cho, Y.T. Dingle, A.P. Morello III, J. Jacob, C.G. Thanos, E. Mathiowitz, Unique insights into the intestinal absorption, transit, and subsequent biodistribution of polymer-derived microspheres, Proc. Natl. Acad. Sci. U. S. A. 110 (2013) 13803-13808.

[193] R.A. Jain, The manufacturing techniques of various drug loaded biodegradable poly(lactide-co-glycolide) (PLGA) devices, Biomaterials 21 (2000) 2475-2490.

[194] M.S. Shive, J.M. Anderson, Biodegradation and biocompatibility of PLA and PLGA microspheres, Adv. Drug Deliv. Rev. 28 (1997) 5-24.

[195] K.A. Woodrow, M.J. Wood, J.K. Saucier-Sawyer, C. Solbrig, W.M. Saltzman, Biodegradable meshes printed with extracellular matrix proteins support micropatterned hepatocyte cultures, Tissue Eng. Part A 15 (2009) 1169-1179.

[196] T. Jung, W. Kamm, A. Breitenbach, E. Kaiserling, J.X. Xiao, T. Kissel, Biodegradable nanoparticles for oral delivery of peptides: is there a role for polymers to affect mucosal uptake? Eur. J. Pharm. Biopharm. 50 (2000) 147-160.

[197] T.E. Rajapaksa, K.M. Bennett, M. Hamer, C. Lytle, V.G. Rodgers, D.D. Lo, Intranasal M cell uptake of nanoparticles is independently influenced by targeting ligands and buffer ionic strength, J. Biol. Chem. 285 (2010) 23739-23746.

[198] P.A. Marx, R.W. Compans, A. Gettie, J.K. Staas, R.M. Gilley, M.J. Mulligan, G.V. Yamshchikov, D. Chen, J.H. Eldridge, Protection against vaginal SIV transmission with microencapsulated vaccine, Science 260 (1993) 1323-1327.

[199] M. Pastor, A. Esquisabel, I. Marquinez, A. Talavera, J.L. Pedraz, Cellulose acetate phthalate microparticles containing Vibrio cholerae: steps toward an oral cholera vaccine, J. Drug Target. 22 (2014) 478-487.

[200] E.S. Cahill, D.T. O'Hagan, L. Illum, A. Barnard, K.H. Mills, K. Redhead, Immune responses and protection against Bordetella pertussis infection after intranasal immunization of mice with filamentous haemagglutinin in solution or incorporated in biodegradable microparticles, Vaccine 13 (1995) 455-462.

[201] K. Misstear, E.A. McNeela, A.G. Murphy, J.A. Geoghegan, K.M. O'Keeffe, J. Fox, K. Chan, S. Heuking, N. Collin, T.J. Foster, R.M. McLoughlin, E.C. Lavelle, Targeted nasal vaccination provides antibody-independent protection against Staphylococcus aureus, J. Infect. Dis. 209 (2014) 1479-1484.

[202] C. Yan, W.L. Rill, R. Malli, J. Hewetson, H. Naseem, R. Tammariello, M. Kende, Intranasal stimulation of long-lasting immunity against aerosol ricin challenge with ricin toxoid vaccine encapsulated in polymeric microspheres, Vaccine 14 (1996) 1031-1038.

[203] F.A. Sharp, D. Ruane, B. Claass, E. Creagh, J. Harris, P. Malyala, M. Singh, D.T. O'Hagan, V. Petrilli, J. Tschopp, L.A. O'Neill, E.C. Lavelle, Uptake of particulate vaccine adjuvants by dendritic cells activates the NALP3 inflammasome, Proc. Natl. Acad. Sci. U. S. A. 106 (2009) 870-875.

[204] M.G. Netea, A. Simon, F. van de Veerdonk, B.J. Kullberg, J.W. Van der Meer, L.A Joosten, IL-1beta processing in host defense: beyond the inflammasomes, PLoS Pathog. 6 (2010) e1000661.

[205] F.L. van de Veerdonk, M.G. Netea, C.A. Dinarello, L.A. Joosten, Inflammasome activation and IL-1beta and IL-18 processing during infection, Trends Immunol. 32 (2011) $110-116$.

[206] D.E. Katz, A.J. DeLorimier, M.K. Wolf, E.R. Hall, F.J. Cassels, J.E. van Hamont, R.L. Newcomer, M.A. Davachi, D.N. Taylor, C.E. McQueen, Oral immunization of adult volunteers with microencapsulated enterotoxigenic Escherichia coli (ETEC) CS6 antigen, Vaccine 21 (2003) 341-346.

[207] S.Y. Seong, P. Matzinger, Hydrophobicity: an ancient damage-associated molecular pattern that initiates innate immune responses, Nat. Rev. Immunol. 4 (2004) 469-478.

[208] S.T. Reddy, A.J. van der Vlies, E. Simeoni, V. Angeli, G.J. Randolph, C.P. O'Neil, L.K. Lee, M.A. Swartz, J.A. Hubbell, Exploiting lymphatic transport and complement activation in nanoparticle vaccines, Nat. Biotechnol. 25 (2007) 1159-1164.

[209] R. De Smet, T. Demoor, S. Verschuere, M. Dullaers, G.R. Ostroff, G. Leclercq, L. Allais, C. Pilette, M. Dierendonck, B.G. De Geest, C.A. Cuvelier, beta-Glucan microparticles are good candidates for mucosal antigen delivery in oral vaccination, J. Control. Release 172 (2013) 671-678.

[210] H. Huang, G.R. Ostroff, C.K. Lee, J.P. Wang, C.A. Specht, S.M. Levitz, Distinct patterns of dendritic cell cytokine release stimulated by fungal beta-glucans and toll-like receptor agonists, Infect. Immun. 77 (2009) 1774-1781. 
[211] E.R. Soto, G.R. Ostroff, Characterization of multilayered nanoparticles encapsulated in yeast cell wall particles for DNA delivery, Bioconjug. Chem. 19 (2008) 840-848.

[212] G.D. Brown, S. Gordon, Immune recognition. A new receptor for beta-glucans, Nature 413 (2001) 36-37.

[213] http://www.accessdata.fda.gov/scripts/fcn/gras_notices/grn000239.PDF.

[214] M. De Jesus, G.R. Ostroff, S.M. Levitz, T.R. Bartling, N.J. Mantis, A population of Langerin-positive dendritic cells in murine Peyer's patches involved in sampling beta-glucan microparticles, PLoS ONE 9 (2014) e91002.

[215] S. Cohen, T. Yoshioka, M. Lucarelli, L.H. Hwang, R. Langer, Controlled delivery systems for proteins based on poly(lactic/glycolic acid) microspheres, Pharm. Res. 8 (1991) 713-720.

[216] A.M. De Campos, A. Sanchez, M.J. Alonso, Chitosan nanoparticles: a new vehicle for the improvement of the delivery of drugs to the ocular surface. Application to cyclosporin A, Int. J. Pharm. 224 (2001) 159-168.

[217] R.A. Miller, J.M. Brady, D.E. Cutright, Degradation rates of oral resorbable implants (polylactates and polyglycolates): rate modification with changes in PLA/PGA copolymer ratios, J. Biomed. Mater. Res. 11 (1977) 711-719.

[218] W. Peters, J.R. Brandl, J.D. Lindbloom, C.J. Martinez, C.D. Scallan, G.R. Trager, D.W. Tingley, M.L. Kabongo, S.N. Tucker, Oral administration of an adenovirus vector encoding both an avian influenza A hemagglutinin and a TLR3 ligand induces antigen specific granzyme B and IFN-gamma T cell responses in humans, Vaccine 31 (2013) 1752-1758.

[219] M. Aminu, A.A. Ahmad, J.U. Umoh, M.C. de Beer, M.D. Esona, A.D. Steele, Adenovirus infection in children with diarrhea disease in Northwestern Nigeria, Ann. Afr. Med. 6 (2007) 168-173.

[220] T. Azegami, H. Itoh, H. Kiyono, Y. Yuki, Novel Transgenic Rice-Based Vaccines, Archivum immunologiae et therapiae experimentalis2014.

[221] T. Nochi, H. Takagi, Y. Yuki, L. Yang, T. Masumura, M. Mejima, U. Nakanishi, A. Matsumura, A. Uozumi, T. Hiroi, S. Morita, K. Tanaka, F. Takaiwa, H. Kiyono, Ricebased mucosal vaccine as a global strategy for cold-chain- and needle-free vaccination, Proc. Natl. Acad. Sci. U. S. A. 104 (2007) 10986-10991.

[222] T. Nochi, Y. Yuki, Y. Katakai, H. Shibata, D. Tokuhara, M. Mejima, S. Kurokawa, Y. Takahashi, U. Nakanishi, F. Ono, H. Mimuro, C. Sasakawa, F. Takaiwa, K. Terao, H. Kiyono, A rice-based oral cholera vaccine induces macaque-specific systemic neutralizing antibodies but does not influence pre-existing intestinal immunity, J. Immunol. 183 (2009) 6538-6544.

[223] D. Tokuhara, B. Alvarez, M. Mejima, T. Hiroiwa, Y. Takahashi, S. Kurokawa, M. Kuroda, M. Oyama, H. Kozuka-Hata, T. Nochi, H. Sagara, F. Aladin, H. Marcotte, L.G. Frenken, M. Iturriza-Gomara, H. Kiyono, L. Hammarstrom, Y. Yuki, Ricebased oral antibody fragment prophylaxis and therapy against rotavirus infection, J. Clin. Invest. 123 (2013) 3829-3838.

[224] N. Huyghebaert, A. Vermeire, P. Rottiers, E. Remaut, J.P. Remon, Development of an enteric-coated, layered multi-particulate formulation for ileal delivery of viable recombinant Lactococcus lactis, Eur. J. Pharm. Biopharm. 61 (2005) 134-141.

[225] Y. Lopez, M. Pastor, J.F. Infante, D. Diaz, R. Oliva, S. Fernandez, B. Cedre, T. Hernandez, L. Campos, A. Esquisabel, J.L. Pedraz, V. Perez, A. Talavera, Repeated dose toxicity study of Vibrio cholerae-loaded gastro-resistant microparticles, J. Microencapsul. 31 (2014) 86-92.

[226] Y. Aramaki, H. Tomizawa, T. Hara, K. Yachi, H. Kikuchi, S. Tsuchiya, Stability of liposomes in vitro and their uptake by rat Peyer's patches following oral administration, Pharm. Res. 10 (1993) 1228-1231.

[227] M. Han, S. Watarai, K. Kobayashi, T. Yasuda, Application of liposomes for development of oral vaccines: study of in vitro stability of liposomes and antibody response to antigen associated with liposomes after oral immunization, J. Vet. Med. Sci. 59 (1997) 1109-1114.

[228] A. Delgado, E.C. Lavelle, M. Hartshorne, S.S. Davis, PLG microparticles stabilised using enteric coating polymers as oral vaccine delivery systems, Vaccine 17 (1999) 2927-2938.

[229] A.M. Mowat, O.R. Millington, F.G. Chirdo, Anatomical and cellular basis of immunity and tolerance in the intestine, J. Pediatr. Gastroenterol. Nutr. 39 (Suppl. 3) (2004) S723-S724.

[230] C.C. Whitacre, New insights into oral tolerance, Gastroenterology 119 (2000) 260-263.

[231] M.A. Clark, M.A. Jepson, N.L. Simmons, T.A. Booth, B.H. Hirst, Differential expression of lectin-binding sites defines mouse intestinal M-cells, J. Histochem. Cytochem. 41 (1993) 1679-1687.

[232] N. Foster, M.A. Clark, M.A. Jepson, B.H. Hirst, Ulex europaeus 1 lectin targets microspheres to mouse Peyer's patch M-cells in vivo, Vaccine 16 (1998) 536-541.

[233] E.C. Lavelle, Targeted delivery of drugs to the gastrointestinal tract, Crit. Rev. Ther. Drug Carrier Syst. 18 (2001) 341-386.

[234] I. Lambkin, C. Pinilla, C. Hamashin, L. Spindler, S. Russell, A. Schink, R. Moya-Castro, G. Allicotti, L. Higgins, M. Smith, J. Dee, C. Wilson, R. Houghten, D. O'Mahony, Toward targeted oral vaccine delivery systems: selection of lectin mimetics from combinatorial libraries, Pharm. Res. 20 (2003) 1258-1266.

[235] M. Manocha, P.C. Pal, K.T. Chitralekha, B.E. Thomas, V. Tripathi, S.D. Gupta, R. Paranjape, S. Kulkarni, D.N. Rao, Enhanced mucosal and systemic immune response with intranasal immunization of mice with HIV peptides entrapped in PLG microparticles in combination with Ulex Europaeus-I lectin as M cell target, Vaccine 23 (2005) 5599-5617.
[236] J.M. Pickard, C.F. Maurice, M.A. Kinnebrew, M.C. Abt, D. Schenten, T.V. Golovkina, S.R. Bogatyrev, R.F. Ismagilov, E.G. Pamer, P.J. Turnbaugh, A.V. Chervonsky, Rapid fucosylation of intestinal epithelium sustains host-commensal symbiosis in sickness, Nature 514 (2014) 638-641.

[237] T. Nochi, Y. Yuki, A. Matsumura, M. Mejima, K. Terahara, D.Y. Kim, S. Fukuyama, K. Iwatsuki-Horimoto, Y. Kawaoka, T. Kohda, S. Kozaki, O. Igarashi, H. Kiyono, A novel M cell-specific carbohydrate-targeted mucosal vaccine effectively induces antigenspecific immune responses, J. Exp. Med. 204 (2007) 2789-2796.

[238] J. Pappo, T.H. Ermak, H.J. Steger, Monoclonal antibody-directed targeting of fluorescent polystyrene microspheres to Peyer's patch M cells, Immunology 73 (1991) 277-280.

[239] F. Zhou, J.P. Kraehenbuhl, M.R. Neutra, Mucosal IgA response to rectally administered antigen formulated in IgA-coated liposomes, Vaccine 13 (1995) 637-644.

[240] N. Hussain, A.T. Florence, Utilizing bacterial mechanisms of epithelial cell entry: invasin-induced oral uptake of latex nanoparticles, Pharm. Res. 15 (1998) 153-156.

[241] X. Wang, D.M. Hone, A. Haddad, M.T. Shata, D.W. Pascual, M cell DNA vaccination for CTL immunity to HIV, J. Immunol. 171 (2003) 4717-4725.

[242] R.M. Steinman, Z.A. Cohn, Identification of a novel cell type in peripheral lymphoid organs of mice. I. Morphology, quantitation, tissue distribution, J. Exp. Med. 137 (1973) 1142-1162.

[243] M.C. Nussenzweig, R.M. Steinman, B. Gutchinov, Z.A. Cohn, Dendritic cells are accessory cells for the development of anti-trinitrophenyl cytotoxic T lymphocytes, J. Exp. Med. 152 (1980) 1070-1084

[244] P.J. Tacken, I.J. de Vries, R. Torensma, C.G. Figdor, Dendritic-cell immunotherapy: from ex vivo loading to in vivo targeting, Nat. Rev. Immunol. 7 (2007) 790-802.

[245] J. Baumann, C.G. Park, N.J. Mantis, Recognition of secretory IgA by DC-SIGN: implications for immune surveillance in the intestine, Immunol. Lett. 131 (2010) 59-66.

[246] A. Pantel, C. Cheong, D. Dandamudi, E. Shrestha, S. Mehandru, L. Brane, D. Ruane, A Teixeira, L. Bozzacco, R.M. Steinman, M.P. Longhi, A new synthetic TLR4 agonist, GLA, allows dendritic cells targeted with antigen to elicit Th1 T-cell immunity in vivo, Eur. J. Immunol. 42 (2012) 101-109.

[247] A. Iwasaki, Mucosal dendritic cells, Annu. Rev. Immunol. 25 (2007) 381-418.

[248] J.D. Smart, The basics and underlying mechanisms of mucoadhesion, Adv. Drug Deliv. Rev. 57 (2005) 1556-1568.

[249] T. Nochi, Y. Yuki, H. Takahashi, S. Sawada, M. Mejima, T. Kohda, N. Harada, I.G. Kong, A. Sato, N. Kataoka, D. Tokuhara, S. Kurokawa, Y. Takahashi, H. Tsukada, S. Kozaki, K. Akiyoshi, H. Kiyono, Nanogel antigenic protein-delivery system for adjuvant-free intranasal vaccines, Nat. Mater. 9 (2010) 572-578.

[250] Y. Yuki, T. Nochi, I.G. Kong, H. Takahashi, S. Sawada, K. Akiyoshi, H. Kiyono, Nanogel-based antigen-delivery system for nasal vaccines, Biotechnol. Genet. Eng. Rev. 29 (2013) 61-72.

[251] Y. Fukuyama, Y. Yuki, Y. Katakai, N. Harada, H. Takahashi, S. Takeda, M. Mejima, S. Joo, S. Kurokawa, S. Sawada, H. Shibata, E.J. Park, K. Fujihashi, D.E. Briles, Y. Yasutomi, H. Tsukada, K. Akiyoshi, H. Kiyono, Nanogel-based pneumococcal surface protein A nasal vaccine induces microRNA-associated Th17 cell responses with neutralizing antibodies against Streptococcus pneumoniae in macaques, Mucosal Immunol. (2015), http://dx.doi.org/10.1038/mi.2015.5 [Epub ahead of print].

[252] A. Kazunari, H. Kiyono, Y. Yoshikazu, N. Tomonori, Mucosal vaccine using cationic + nanogel, 2010. (https://patentscope.wipo.int/search/en/detail.jsf? docld $=$ WO2010050578\&recNum $=212 \&$ docAn $=$ JP2009068647\&queryString=\%28\%28et/adjuvant\%29\%20or\%20\%28ABE/adjuvant\%29\%29\%20AND\%20\%28\%28ET/vaccine\%29\%20or\%20\%28ET/immunogenic\%29\%20or\%20\%28ET/antigen\%29\%200R\%20\%28ABE/vaccine\%29\%20or\%20\% 28ABE/immunogenic\%29\%20or\%20\%28ABE/antigen\%29\%29\&maxRec=1307).

[253] L.S. Velasquez, S. Shira, A.N. Berta, J. Kilbourne, B.M. Medi, I. Tizard, Y. Ni, C.J. Arntzen, M.M. Herbst-Kralovetz, Intranasal delivery of Norwalk virus-like particles formulated in an in situ gelling, dry powder vaccine, Vaccine 29 (2011) 5221-5231.

[254] J. Kunisawa, A. Okudaira, Y. Tsutusmi, I. Takahashi, T. Nakanishi, H. Kiyono, T. Mayumi, Characterization of mucoadhesive microspheres for the induction of mucosal and systemic immune responses, Vaccine 19 (2000) 589-594.

[255] L. Illum, I. Jabbal-Gill, M. Hinchcliffe, A.N. Fisher, S.S. Davis, Chitosan as a novel nasal delivery system for vaccines, Adv. Drug Deliv. Rev. 51 (2001) 81-96.

[256] M. Thanou, J.C. Verhoef, H.E. Junginger, Chitosan and its derivatives as intestinal absorption enhancers, Adv. Drug Deliv. Rev. 50 (Suppl. 1) (2001) S91-S101.

[257] A. Mori, E. Oleszycka, F.A. Sharp, M. Coleman, Y. Ozasa, M. Singh, D.T. O'Hagan, L. Tajber, O.I. Corrigan, E.A. McNeela, E.C. Lavelle, The vaccine adjuvant alum inhibits IL-12 by promoting PI3 kinase signaling while chitosan does not inhibit IL-12 and enhances Th1 and Th17 responses, Eur. J. Immunol. 42 (2012) 2709-2719.

[258] J. Clemens, J. Holmgren, When, how, and where can oral cholera vaccines be used to interrupt cholera outbreaks? Curr. Top. Microbiol. Immunol. 379 (2014) 231-258.

[259] D. Sur, S. Kanungo, B. Sah, B. Manna, M. Ali, A.M. Paisley, S.K. Niyogi, J.K. Park, B Sarkar, M.K. Puri, D.R. Kim, J.L. Deen, J. Holmgren, R. Carbis, R. Rao, T.V. Nguyen, S.H. Han, S. Attridge, A. Donner, N.K. Ganguly, S.K. Bhattacharya, G.B. Nair, J.D. Clemens, A.L. Lopez, Efficacy of a low-cost, inactivated whole-cell oral cholera vaccine: results from 3 years of follow-up of a randomized, controlled trial, PLoS Negl. Trop. Dis. 5 (2011) e1289. 